\title{
Exploiting remote sensing land surface temperature in distributed hydrological modelling: the example of the Continuum model
}

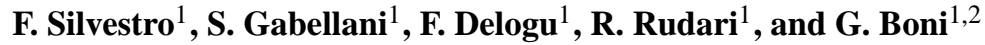 \\ ${ }^{1}$ CIMA research foundation, Savona, Italy \\ ${ }^{2}$ DIBRIS, University of Genova, Genova, Italy \\ Correspondence to: F. Silvestro (francesco.silvestro@cimafoundation.org) \\ Received: 24 May 2012 - Published in Hydrol. Earth Syst. Sci. Discuss.: 14 June 2012 \\ Revised: 12 December 2012 - Accepted: 20 December 2012 - Published: 11 January 2013
}

\begin{abstract}
Full process description and distributed hydrological models are very useful tools in hydrology as they can be applied in different contexts and for a wide range of aims such as flood and drought forecasting, water management, and prediction of impact on the hydrologic cycle due to natural and human-induced changes. Since they must mimic a variety of physical processes, they can be very complex and with a high degree of parameterization. This complexity can be increased by necessity of augmenting the number of observable state variables in order to improve model validation or to allow data assimilation.

In this work a model, aiming at balancing the need to reproduce the physical processes with the practical goal of avoiding over-parameterization, is presented. The model is designed to be implemented in different contexts with a special focus on data-scarce environments, e.g. with no streamflow data.
\end{abstract}

All the main hydrological phenomena are modelled in a distributed way. Mass and energy balance are solved explicitly. Land surface temperature (LST), which is particularly suited to being extensively observed and assimilated, is an explicit state variable.

A performance evaluation, based on both traditional and satellite derived data, is presented with a specific reference to the application in an Italian catchment. The model has been firstly calibrated and validated following a standard approach based on streamflow data. The capability of the model in reproducing both the streamflow measurements and the land surface temperature from satellites has been investigated.

The model has been then calibrated using satellite data and geomorphologic characteristics of the basin in order to test its application on a basin where standard hydrologic observations (e.g. streamflow data) are not available. The results have been compared with those obtained by the standard calibration strategy based on streamflow data.

\section{Introduction}

Continuous streamflow simulation is of fundamental importance in the support of water management decisions (e.g. best use of water resources) and civil protection actions (e.g. flood and drought mitigation actions) (Schlosser et al., 1997; Middelkoop et al., 2001; Karsten et al., 2002; Bartholomes and Todini, 2005). These are only some examples of the huge variety of cases where continuous hydrological models have been applied. The application of models to different problems resulted in the development of a number of hydrological models, which sometimes showed very different characteristics (e.g. Beven, 1997; Todini and Ciarapica, 2001; Rigon et al., 2006).

Over recent decades computation capacity has developed exponentially. Meanwhile, due to the progress of Earth observation techniques, a large amount of territorial information (digital elevation models, land use, soil and vegetation parameters) has become readily available. As result of this, full process description and distributed hydrological modelling, assisted by detailed catchment descriptions, has become feasible, leading to the improvement in the understanding and representation of both runoff formation and propagation dynamics (Winchell et al., 1998; Giannoni et al., 2000). Distributed modelling allows us to understand the role played by space and time rainfall distribution (Giannoni et al., 2003), by soil and vegetation heterogeneity, and by the

Published by Copernicus Publications on behalf of the European Geosciences Union. 
drainage network structure (Downer et al., 2002; Giannoni et al., 2000, 2005).

Several hydrological models are based on a detailed description of all the main hydrological processes so that they can provide a continuous simulation in support of specific tasks such as long-term water balances and flood forecasting. Some examples starting from the early 1970s can be cited: Sacramento model (Burnash et al., 1973; Burnash, 1995), SHE (Abbott et al., 1986), RIBS (Garrote and Brass, 1995), CASC2D (Julien et al., 1995), TOPMODEL (Beven, 1997; Wang et al., 2006), TOPKAPI (Todini and Ciarapica, 2001), GEOtop (Rigon et al., 2006), and MOBIDIC (Campo et al., 2006). They can usually work in different regimes and simulate continuously the spatiotemporal evolution of the state of the catchment. The advantages of these types of models have been highlighted in various works (e.g. Bartholomes and Todini, 2005; Liu et al., 2005; Castelli et al., 2009).

The use of models capable of exploiting distributed information has consolidated, with the penalty of increasing the number of model parameters with the associated problem of reliably estimating them (Abbott et al., 1986; Beven, 1993; Madsen, 2000; Anderson et al., 2006).

Because of the detailed and complete description of the hydrological cycle, these advanced models are characterized by an abundant number of parameters, which need a detailed knowledge of the catchment to which they are applied. Some of them, such as those describing soil physics and land use, have a direct physical meaning. They can therefore be estimated on the basis of maps of catchment information and geophysical cartography exploiting also the continuous improvement of satellite-derived information; nevertheless, the scale of representation, the detail and the temporal updating of information often do not match requirements for the reliable estimation of these parameters. Furthermore, relationships between land information and model parameters are sometimes indirect and affected by great uncertainty, nullifying, in practical applications, the benefit of an accurate process description.

The presence of many parameters, in general, allows modellers to obtain good results in the calibration phase because of the adaptation skills of the model; however, this leads to an increased probability of obtaining similar results with different parameter sets (Beven and Binley, 1992; Beven and Freer, 2001; Savenije, 2001). This limits the possibility of reliable parameter estimation, hampering the prediction of the abilities of the model. There are two ways to face this issue: develop a parsimonious model or increase the means of identifying parameters from available data. The design of the "Continuum" model is based on a combination of the abovementioned strategies. On the one hand, special attention is paid to reducing, as much as possible, the parameterization of the physical processes so that land information can be extensively used as a constraint to parameter calibration. On the other hand, the model parsimony has to be compatible with the necessity for a detailed description of all the terms of the hydrological cycle. This results in an increased number of observables in the model state variables, in order to exploit the potential offered by today's remote sensing (R. S.).

In the last decade many advances in satellite data development and analysis for Earth observation have been reached. R. S. provides inputs to the model (e.g. meteorological input, catchment description, vegetation characterization) or observation of the state variables (e.g. soil moisture, land surface temperature). It is therefore a concern for new models to include prognostic equations of satellite observables so that they can be used in the calibration/validation phase, or as constraints in a data assimilation framework (Winsemius et al., 2006; Kumar et al., 2008).

The Continuum model aims at an equilibrium between simplicity and rigorous physical modelling while maintaining comparable performances to existing models; this is demonstrated by a calibration and validation exercise using standard methods and data. The reduced complexity of the schematizations and the relatively small number of parameters leads to a considerably lower calibration effort, increasing model robustness and portability to data-scarce environments; along these lines this work proposes a novel calibration methodology based on remotely sensed data only.

The article is organized as follows. In chapter two the components of the model are presented; chapter three describes the model's sensitivity analysis, the case study, as well as the parameter calibration and model validation; the chapter includes the calibration experiment carried out using only R. S.-derived information (i.e. LST - land surface temperature - data and morphological information); chapter four contains discussion and conclusions.

\section{Model description}

Continuum is a continuous, distributed hydrological model that strongly relies on a morphological approach, based on a novel way for the drainage network component identification (Giannoni et al., 2005). Continuum is designed to be applied on a wide range of catchment classes, from small $\left(\mathrm{O}(\right.$ Area $\left.)=10^{1}: 10^{2} \mathrm{~km}^{2}\right)$ to medium $\left(\mathrm{O}(\right.$ Area $\left.)=10^{3} \mathrm{~km}^{2}\right)$ size basins and with time resolutions lower than $24 \mathrm{~h}$. Such scales are normally modelled using data-intense models (e.g. DHI, 2003), and application of such models to basins with $\mathrm{O}$ (Area) $>10^{3} \mathrm{~km}^{2}$ is possible (e.g. Bartholomes and Todini, 2005), but the data demand in order to have a reliable implementation is usually very high.

The basin is represented using a regular square mesh based on digital elevation model (DEM); the flow directions are identified using a D-8 approach (O'Callaghan and Mark, 1984). The drainage network is represented distinguishing between hillslope and channelled flow with a filter defined by the expression $A S^{k}=C$ where $A$ is the contributing area upslope of each cell [ $\left.\mathrm{L}^{2}\right]$ and $S$ the modified local slope [-] (Giannoni et al., 2000). The exponent $k[-]$ is a function of 


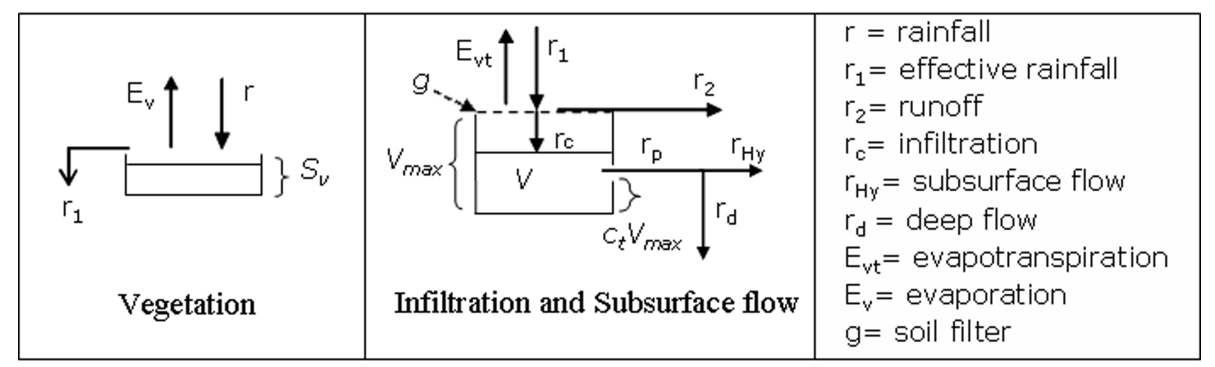

Fig. 1. Sketches of vegetation retention and subsurface flow at cell scale. $S_{\mathrm{V}}$ is the capacity of the vegetation reservoir, $V_{\mathrm{max}}$ the capacity of the soil reservoir, $V$ the actual water volume in the soil and $c_{\mathrm{t}} V_{\max }$ the field capacity of the soil.

the morphologic environment in which the network developed and weighs the importance between flow accumulation and slope in determining active channelled flow (Giannoni et al., 2000). In mature morphological environments, $k$ can be set equal to 1.7 (Giannoni et al., 2003) while the threshold $C$ can be calibrated following fractal theory (Giannoni et al., 2005) and reproducing topographic independent information like the so-called "blue lines".

Infiltration and subsurface flow is described using a semiempirical, but quite detailed, methodology based on a modification of Horton algorithm (Bauer, 1974; Disikin and Nazimov, 1997) and focuses especially on exploiting land use and climatology information, which are easily available, to set the infiltration parameters. The energy balance is based on the so-called "force-restore equation" (Dickinson, 1988), which balances forcing and restoring terms, with explicit soil surface temperature prognostic computation. The overland runoff is distributed with differentiation between hillslope and channel flow. Vegetation interception and water table flow have been also schematized. The different approaches are detailed in the following paragraphs.

\subsection{Overland and channel flow}

The surface flow schematization distinguishes between channel and hillslope flow. In channels the momentum equation per unit of width is derived from the kinematic schematization (Wooding, 1965; Todini and Ciarapica, 2001) with a nonlinear dependence between discharge and water velocity (see Appendix A for details on the equations).

The water depth for the $i$-th channel cell is evaluated combining the momentum equation and the mass balance equation (Liu et al., 2005):

$\frac{\mathrm{d} h_{i}}{\mathrm{~d} t}=I_{\mathrm{i}}-\frac{1}{\Delta x} \cdot u_{\mathrm{c}} \cdot \sqrt{\operatorname{tg}\left(\beta_{i}\right)} \cdot h_{i}^{1.5}$

where $I_{\mathrm{i}}$ represents the input per unit of area (the sum of runoff, saturation excess and inflow discharge from upstream) to the grid cell $\left[\mathrm{L} \mathrm{T}^{-1}\right]$.

On the hillslopes the overland flow has a linear equation for the motion:

$q=\Delta x \cdot u_{\mathrm{h}} \cdot h_{i}$ where $u_{\mathrm{h}}$ parameterizes the main morphologic characteristics of the hillslopes $\left[\mathrm{T}^{-1}\right]$ (slope, roughness, etc.). The final schematization is equivalent to a linear reservoir model.

The parameters $u_{\mathrm{h}}$ and $u_{\mathrm{c}}$ need calibration at basin scale (i.e. one value for the entire catchment).

In both hillslopes and channels, the re-infiltration process is accounted for: the input to the $i$-th cell must exceed its infiltration capacity; otherwise, it infiltrates the soil. Exfiltration is also possible.

\subsection{Vegetation interception}

Interception includes the portion of rainfall that is caught by tree leaves, grass and vegetation cover in general, and is evaporated before it touches the ground. Ponding effects are also included in this initial abstraction. Interception is modelled by a simple empirical equation similar to the one used by Rey (1999), Kozak et al. (2007), Zhao (2003), among others. A maximum retention capacity $S_{\mathrm{v}}$ is introduced, and it is estimated as a function of the leaf area index (LAI) by the relationship (Kozak et al., 2007):

$S_{\mathrm{v}}=0.95+0.5 \cdot \mathrm{LAI}-0.06 \cdot \mathrm{LAI}^{2}[\mathrm{~L}]$.

The water in the reservoir with capacity $S_{\mathrm{v}}$ is evaporated at the evaporation rate derived by the latent heat flux estimation (see Sect. 2.5) without affecting the infiltration computation; the input is the precipitation (see Fig. 1). The advantage of using a LAI-dependent expression is that the model takes into account vegetation variability in space and time. LAI is usually updated every 15 days from satellite optical sensor data (e.g. from MODIS).

\subsection{Infiltration and subsurface flow}

The infiltration methodology is a modification of the Horton equation (Diskin and Nazimov, 1994; Gabellani et al., 2008) based on physically interpretable parameters. It accounts for soil moisture evolution even in condition of intermittent and low-intensity rainfall (namely lower than the infiltration capacity of the soil). 
The soil is schematized as a reservoir with capacity $V_{\max }$ [L], and a selective filter $g(t)\left[\mathrm{L} \mathrm{T}^{-1}\right]$ manages the inflow:

$g(t)=f_{0}+\left(f_{1}-f_{\mathrm{o}}\right) \cdot \frac{V(t)}{V_{\max }}$

where $f_{0}$ is the maximum infiltration rate for completely dry soils and $f_{1}$ is the asymptotic minimum infiltration rate for saturated soils considered as a function of $f_{0}$ (Mishra and Singh, 2003):

$f_{1}=c_{\mathrm{f}} f_{0}$

The method proposed by Gabellani et al. (2008) has been further modified by introducing the field capacity of the soil, defined as the water content that can be held by capillarity against the force of gravity:

$V_{\mathrm{fc}}=c_{\mathrm{t}} V_{\max }$

with the parameter $c_{\mathrm{t}} \in[0,1]$. In this new configuration (see Fig. 1), the dynamic mass-balance equation for the soil can be written for each cell:

$\frac{\mathrm{d} V}{\mathrm{~d} t}=g(t)-r_{\mathrm{p}}(t)$

where

$r_{\mathrm{p}}(t)=f_{1} \frac{V(t)-c_{\mathrm{t}} V_{\max }}{V_{\max }\left(1-c_{\mathrm{t}}\right)}$.

The details of dynamic mass balance equations are described in Appendix B.

The infiltration scheme has four parameters: the initial infiltration rate $f_{0}$, the maximum soil retention capacity $V_{\max }$, and the parameters to define soil field capacity $c_{\mathrm{t}}$ and final infiltration rate $c_{\mathrm{f}}$. The parameters $f_{0}$ and $V_{\max }$ are related to the soil type and land use through the curve number $(\mathrm{CN})$ parameter (Risse et al., 1995). Following Gabellani et al. (2008) they can be easily derived by soil use and soil type maps and they vary spatially in the catchment. $c_{\mathrm{t}}$ and $c_{\mathrm{f}}$ are calibration parameters and are assumed to be constant for the whole basin. In this way the pattern of $f_{1}$ and $V_{\mathrm{fc}}$ is spatially modulated by the pattern of $V_{\max }$.

The percolation rate separates into two components: a contribution to subsurface flow $r_{\mathrm{Hy}}$ and one to deep flow $r_{\mathrm{d}}$ or recharging water table defined as

$r_{\mathrm{Hy}}=\sin \alpha \cdot r_{\mathrm{p}}(t)$

$r_{\mathrm{d}}=(1-\sin \alpha) \cdot r_{\mathrm{p}}(t)$

where the angle $\alpha$ is such that $\operatorname{tg}(\alpha)$ is the downslope index as in Hjerdt et al. (2004); $\sin (\alpha)$ is a decomposition term that increases with the terrain slope, reproducing the major proneness of the high slope areas to subsurface flow due to gravity. The downslope index seems to be less sensitive than local surface slope to changes in DEM resolution, and it is able to capture dominant controls on local drainage regimes, especially in cases where profile curvature exerts a strong control on the drainage pattern (see Hjerdt et al., 2004 for details on this issue).

The subsurface flow is propagated between cells following the surface drainage network directions, and the soil moisture state of each cell is updated by considering both the infiltration, estimated by the modified Horton method, and the inflow from the upper cells. Therefore a cell can reach saturation because of the percolation from upper cells causing saturation excess (Dunne and Black, 1970).

\subsection{Deep flow and water table}

Several approaches are possible to describe the dynamics of both the deep flow and the water table, with examples from Darcy's law applications to conceptual reservoir models (Todini and Ciarapica, 2001; Rigon et al., 2006; Campo et al., 2006). However, it is often difficult to have the data necessary for the correct implementation and parameterization of water table dynamics (Castelli et al., 2009).

In Continuum the water table evolution is modelled with a simplified approach that maintains a physical and distributed description of the process. Above all we are interested in the water table interaction with the subsurface flow and soil surface and in its effects on surface flow and soil moisture spatial pattern; the adopted scheme allows also the reproduction of the baseflow far from rainfall events with a parsimonious parameterization.

The layer of soil containing the aquifer is schematized as a unique homogeneous layer bounded by the lower impervious (bedrock) surface and the bottom of the root zone. The thickness of this layer is expressed in terms of maximum volume of water content of the aquifer, and it is estimated by following Saulnier et al. (1997) using the surface slope as a proxy. The maximum water content in every cell $(i)$ of the basin is given by

$V_{\mathrm{W}_{\mathrm{mi}}}=V_{\mathrm{W}_{\max }} \cdot\left(\frac{\operatorname{tg}\left(\alpha_{\max }\right)-\operatorname{tg}\left(\alpha_{i}\right)}{\operatorname{tg}\left(\alpha_{\max }\right)-\operatorname{tg}\left(\alpha_{\min }\right)}\right)$

where $V_{\mathrm{W}_{\max }}$ is the absolute maximum water content of the aquifer on the whole investigated area; this sets a limit that is basically a calibration parameter (see Fig. 2). The reservoir is fed with $r_{\mathrm{d}}$ (see previous section).

The effect of porosity is considered as a multiplicative factor in the Darcy's equation used to estimate the flux per unit area between two contiguous cells $(i$ and $j)$ :

$q_{i j}=\frac{h_{\mathrm{W} i}-h_{\mathrm{W} j}}{\Delta x} \cdot R_{\mathrm{f}} \cdot f_{1 \mathrm{i}}$

where $\Delta x$ is the DEM spatial resolution, $f_{1 \mathrm{i}}$ the final infiltration rate estimated as in Eq. (5), $h_{\mathrm{W}}$ the water table level (for details on the equation defining $h_{\mathrm{W}}$, see Appendix C) and $R_{\mathrm{f}}$ a factor that also takes care of differentiating the saturated 


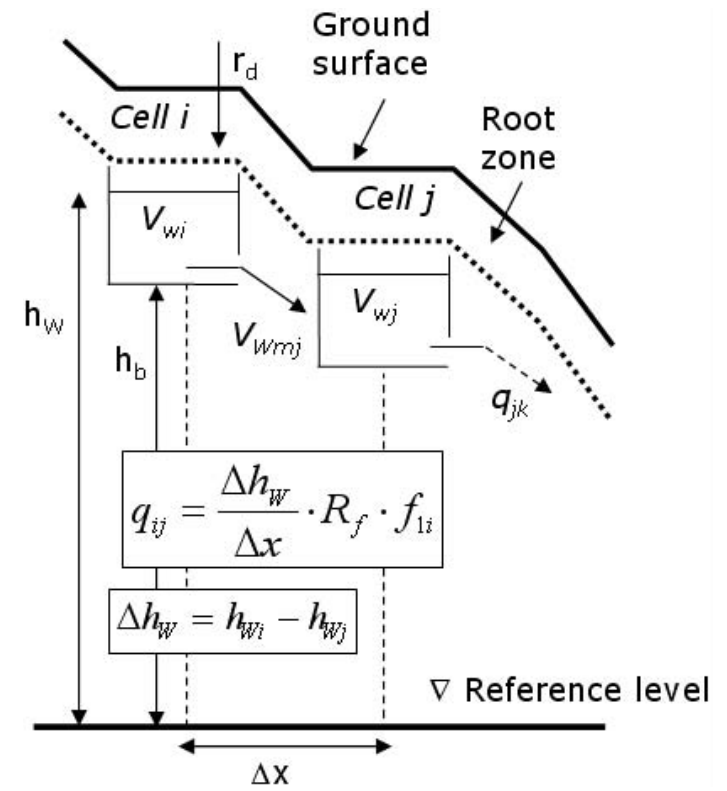

Fig. 2. Sketch of water table flow. As an example two consecutive cells have been considered. The flow is calculated using the water table gradient between the cells. $r_{\mathrm{d}}$ is the deep flow, $V_{\mathrm{W}}$ the water table actual water content, $V_{\mathrm{Wm}}$ the water table maximum water content, $h_{\mathrm{W}}$ the absolute level of water table, $h_{\mathrm{b}}$ the absolute level of impermeable soil layer, $R_{\mathrm{f}}$ a model parameter and $\Delta x$ the model spatial resolution.

vertical and horizontal conductivity. Each cell can drain towards all the neighbouring cells following the 2-D water table gradient that depends on the elevation and on the water content of each cell.

When the water table reaches the surface $\left(V_{\mathrm{W} i}(t)=V_{\mathrm{W}_{\mathrm{mi}}}\right)$, the deep percolation term in Eq. (9) is inhibited, while the condition $V_{\mathrm{W}}(t) \cong 0$ is a limit that can only be reached after a very long and anomalous dry period.

\subsection{Energy balance and evapotranspiration}

The representation of surface mass and energy turbulent fluxes requires the solution of a conservation equation for mass and energy (Deardorff, 1978) driven by temperature and moisture content. Since the vertical gradient of such variables is quite large, a high-resolution multiple layer model would be required to estimate soil surface temperature and moisture content with accuracy. Such an approach demands substantial amounts of computing resources to solve the balance equations. An alternative approach makes use of computationally efficient parameterization of soil heat and moisture flux terms. Bhumralkar (1975) and Blackadar (1976) independently showed that the heat flux into the soil could be parameterized by the sum of a temperature-derivative term and the difference between ground surface and deep soil temperature. Deardorff (1978) referred to this approach as the "force-restore" method, because the forcing by net radiation is modified by a restoring term that contains the deep soil temperature. Since then the "force-restore" method has been widely used in land surface modelling (e.g. Lin, 1980; Dickinson, 1988; Dickinson et al., 1993; Noihan and Planton, 1989; Caparrini et al., 2004). Hu and Islam (1995) demonstrated that the "force-restore" equation is the solution of the heat diffusion equation, with purely sinusoidal forcing assuming that the thermal properties are constant with depth and the surface forcing term is also nearly independent of air temperature and has a strong periodic behaviour in time.

The Continuum model solves a complete and explicit energy balance at the interface between soil surface and atmosphere by using the "force-restore" approach for land surface temperature (Dickinson, 1988). Theoretically, the control volume to which the balance is applied is the unit area bounded vertically by the surface of the soil and the top of the canopy, assuming the thermal capacity of this volume is negligible. The horizontal energy fluxes are neglected. In practice, the volume is extended to the unit cell of the numerical scheme used. This approximation is a fair trade-off between parsimony in parameterization and accuracy in the description of the processes (Boni et al., 2001; Sini et al., 2008).

The conservation of energy at soil surface is given by

$G=R_{\mathrm{n}}-H-\mathrm{LE}$

where $R_{\mathrm{n}}$ is the net radiation, $H$ the sensible heat flux, LE the latent heat flux and $G$ the ground flux (all $\left[\mathrm{Et}^{-1} \mathrm{~L}^{-2}\right]$ ). This latter term closes the budget, and it represents the heat propagated by diffusion towards the deep layers of the soil. The shortwave component of $R_{\mathrm{n}}$ is derived from radiometer observations when the density of observations is appropriate. Otherwise, it is estimated by combining the extraterrestrial component of the radiation computed on the basis of Yang et al. (2001, 2006), attenuated using meteorological variables and cloud cover (including MSG cloud cover). The terrain parameter characterizations that influence both direct and diffuse components of the radiation are computed following the approach in Dozier and Frew (1990). The longwave components are rarely available from observations, and they are therefore estimated using the Stefan-Boltzmann law as a function of air temperature and humidity.

The daily cycle of LST has the implicit signature of the energy balance. Maximum amplitudes of LST diurnal cycle are usually reached in the presence of bare and dry soil. The presence of moisture on the surface and in the subsurface soil greatly moderates the daily range of LST. The vegetation cover has a similar effect. The "force-restore" approach leads to the following equation for LST:

$\frac{\mathrm{dLST}}{\mathrm{d} t}=2 \cdot \sqrt{\pi \omega}\left(\frac{R_{\mathrm{n}}-H-\mathrm{LE}}{\varphi}\right)-2 \pi \varpi \cdot\left(\mathrm{LST}-T_{\mathrm{deep}}\right)$

where $\varphi\left[\mathrm{EL}^{-2} \mathrm{~T}^{-1} \mathrm{t}^{-(1 / 2)}\right]$ is the effective thermal inertia and $T_{\text {deep }}[\mathrm{T}]$ is a "restoring" deep ground temperature. $T_{\text {deep }}$ 


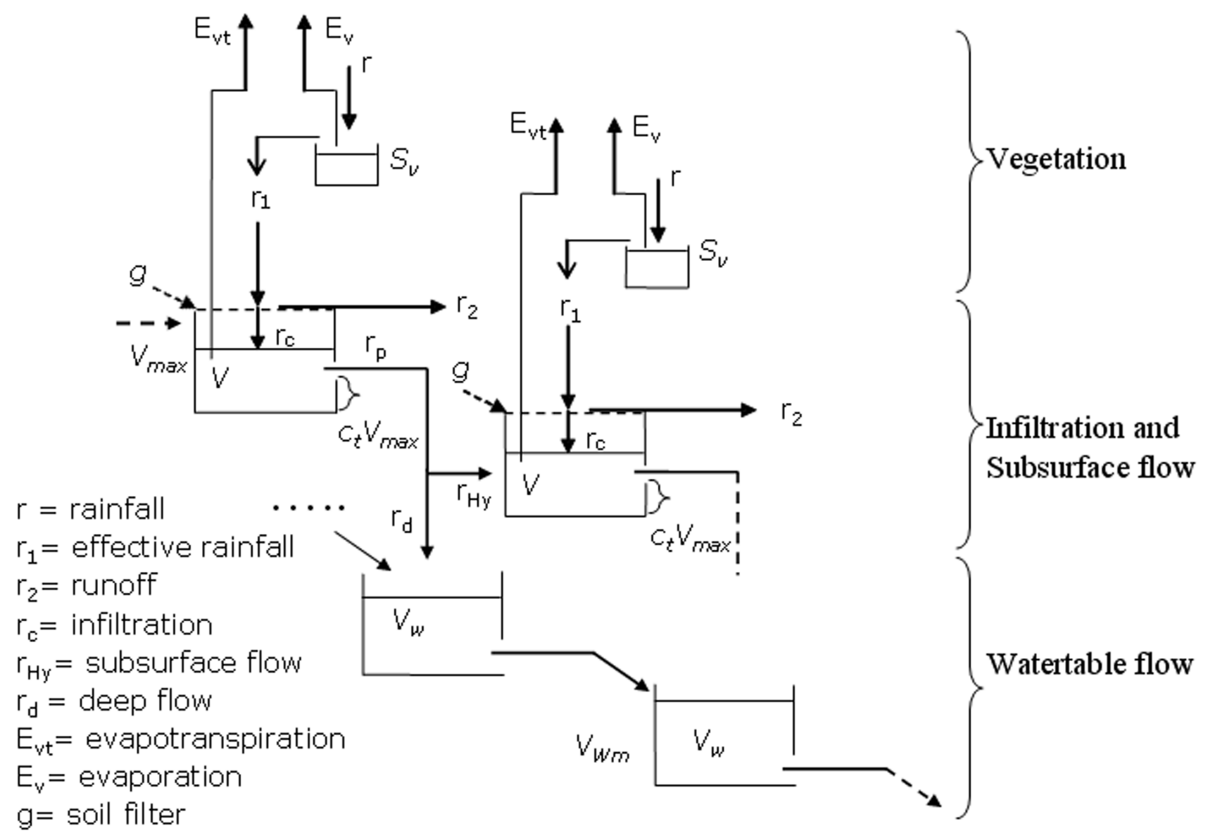

Fig. 3. Sketch of flux partition in the Continuum model with the integration of the single modules. Two consecutive cells are illustrated.

is evaluated by filtering data for air temperature at ground level (Caparrini et al., 2003; Caparrini and Castelli, 2004). $\varphi$ is the thermal inertia, and it is a function of conductivity, density and specific heat capacity of soil, and it is eventually related to soil moisture. The fluxes are estimated using bulk formulations. Details about the component of the energy balance and its parameterization are reported in Appendix $\mathrm{D}$. The equation input variables are commonly observed by ground-based micrometeorological networks. The soil parameters used in the estimation of the thermal inertia, usually constant at basin scale, can be estimated by a data assimilation process, or related to soil type (Peters et al., 1997) when reliable maps are available.

In Continuum the evapotranspiration ET $\left[\mathrm{m} \mathrm{s}^{-1}\right]$ is estimated as

$\mathrm{ET}=\frac{\mathrm{LE}}{\rho_{\mathrm{w}} \cdot \lambda_{\mathrm{LE}}}$

where $\rho_{\mathrm{W}}\left[\mathrm{mL}^{-3}\right]$ is the water density, and ET is deducted from the interception storage $S_{\mathrm{v}}$ if not empty, otherwise from the subsurface reservoir $V(t)$ adding the following terms to Eq. (B1) in Appendix:

$$
\left\{\begin{array}{l}
\frac{\mathrm{d} S_{\mathrm{v}}}{\mathrm{d} t}=\text { ET if } S_{\mathrm{v}}>0 \\
\frac{\mathrm{d} V}{\mathrm{~d} t}=\text { ET if } S_{\mathrm{v}}=0
\end{array} .\right.
$$

\subsection{Model summary}

In summary, Continuum is a distributed model based on a space-filling representation of the network, directly derived from a DEM. The DEM resolution coincides with the model resolution. The mass and energy balances are solved at cell scale referring to the schematizations of subsurface flow, deep flow and vegetation interception. The overland and channel flow are described by a linear and a nonlinear tank schematization respectively.

Figure 3 offers a sketch of the Continuum structure. Two consecutive cells are considered to highlight the interaction between the single modules.

Continuum can work with different time steps $\left(\Delta t_{\mathrm{m}}\right)$, generally smaller than 1 day. Time steps, in the range between $10 \mathrm{~min}$ to $1 \mathrm{~h}$, are appropriate when the objective is a flood simulation in small to medium catchments, and they are consistent with commonly available meteorological data. The overland and channel flow module works with a time step $\left(\Delta t_{\mathrm{s}}\right)$ that is smaller than $\Delta t_{\mathrm{m}}$, dependent on the DEM resolution to avoid problems of numerical stability. The mass-balance equations are integrated using the Heun time stepping scheme (Clark and Kavetski, 2010), which is a semi-implicit method (predictor-corrector scheme), and it is second-order accurate. Such a choice allows a good balance between accuracy of the solution and performance when an appropriate time step is used (this would change in applications where the integration step is large, e.g. daily). A different scheme is used to solve the "force-restore" equation where more accuracy is needed and a Runge-Kutta forthorder method is used. Since small time steps are used, minor effects due to the adopted time stepping scheme can be expected (Clark and Kavetski, 2010).

Six model parameters need calibration on the basis of input-output time series: $c_{\mathrm{f}}, c_{\mathrm{t}}, u_{\mathrm{h}}, u_{\mathrm{c}}, R_{\mathrm{f}}, V_{\mathrm{Wmax}}$ (see Table 1). The first two parameters $c_{\mathrm{f}}$, and $c_{\mathrm{t}}$ mainly rule the generation of runoff and the movement of water in the different 
Table 1. Summary of the model parameters that need calibration with their brief description.

\begin{tabular}{ll}
\hline Parameter & Description \\
\hline$u_{\mathrm{h}}\left[\mathrm{s}^{-1}\right]$ & Flow motion coefficient in hillslopes \\
$u_{\mathrm{c}}\left[\mathrm{m}^{0.5} \mathrm{~s}^{-1}\right]$ & Friction coefficient in channels \\
$c_{\mathrm{f}}[-]$ & Defines the infiltration capacity at saturation \\
$c_{\mathrm{t}}[-]$ & Defines the mean field capacity \\
$R_{\mathrm{f}}[-]$ & $\begin{array}{l}\text { Related to anisotropy between the vertical and horizontal } \\
\text { saturated conductivity, and to soil porosity }\end{array}$ \\
$V_{\mathrm{Wmax}}[\mathrm{mm}]$ & $\begin{array}{l}\text { Maximum water capacity of the aquifer on the } \\
\text { whole investigated area }\end{array}$ \\
\hline
\end{tabular}

soil layers, while $u_{\mathrm{h}}$ and $u_{\mathrm{c}}$ control the surface water motion. $V_{\text {Wmax }}$ represents the maximum storage capacity of the aquifer, and $R_{\mathrm{f}}$ summarizes the effect of soil porosity as well as of the ratio between vertical and horizontal saturated soil conductivity.

\section{Case study: Orba watershed}

\subsection{Watershed description}

The model has been tested on the Orba basin located in the southern part of the Piemonte region in the Apennines (see Fig. 4). The Orba River originates from Mt. Reixa (1183 ma.s.1.) in the Beigua Massif, and it flows into the Bormida River, a tributary of the Tanaro River, before it reaches the town of Alessandria. Three main morphological areas can be identified: a mountain part characterized by very steep sub-catchments with a very deep river bed, a mild part with an average slope of $1 \%$, and finally the alluvial part characterized by very small slope values. The Orba River has mainly a torrential regime with recurrent flash floods during the autumn and spring rainfall seasons and very low flows during summer. The Orba mean annual flow in correspondence of the confluence with Bormida River is around $20 \mathrm{~m}^{3} \mathrm{~s}^{-1}$ (here the drainage area is about $810 \mathrm{~km}^{2}$ ).

\subsection{Dataset}

The micrometeorological networks of Liguria and Piemonte Italian regions provide meteorological inputs. In the Orba basin there are 31 rain gauges, 27 thermometers, 6 hygrometers, 4 radiometers (shortwave) and 4 anemometers. The temporal resolution of the observations is $1 \mathrm{~h}$. This latter is also the temporal resolution used in the model application $\left(\Delta t_{\mathrm{m}}=1 \mathrm{~h}\right)$. The overland and channel flow module uses $\Delta t_{\mathrm{s}}=30 \mathrm{~s}$.

Observations from two nested stage discharge gauges, with reliable and constantly updated discharge rating curves, are used for model calibration and validation (Fig. 4). The Tiglieto station $\left(75 \mathrm{~km}^{2}\right)$ is located in the upper part of the basin, characterized by a mountainous morphology with high

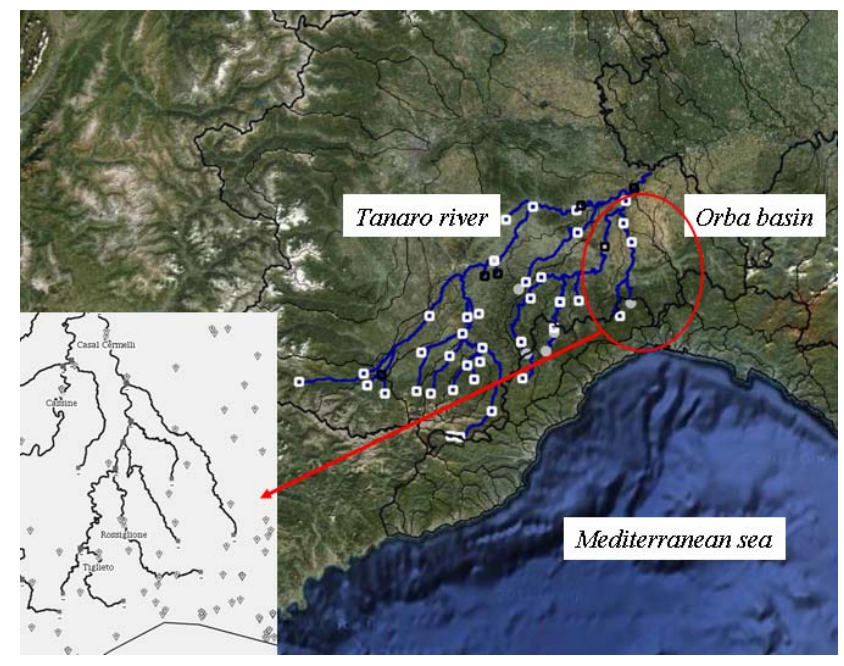

Fig. 4. Orba river location in north-west Italy. In the lower left corner is a zoom on the basin with the micro-meteorological stations. White squares represent the level gauges with rating curve, black squares the level gauges without rating curve.

slopes, and a high percentage of the territory is covered by forest. The Casalcermelli station drains an area of $800 \mathrm{~km}^{2}$, and it is placed in the final part of the basin in a quite flat environment. This allows for the testing of the model on different spatial and temporal scales over the same basin.

Two different periods have been simulated: the calibration period starts from 1 June 2006 and ends on 31 December 2006, while the validation period starts from 1 June 2009 and ends on 31 December 2009. No significant snowfall and accumulation were observed during both periods, allowing the implementation of the model without the need of a module for snow cover and snow melting simulation.

DEM and CN maps with spatial resolution equal to $100 \mathrm{~m}$ are available for the basin. $\Delta x=100 \mathrm{~m}$ is assumed as the model grid size. LAI maps have been produced with temporal update of 15 days as averaged values of daily maps obtained by Meteosat Second Generation (MSG). The LAI product is based on the information provided by the three shortwave channels of MSG-SEVIRI (VIS $0.6 \mu \mathrm{m}$, NIR $0.8 \mu \mathrm{m}$, SWIR $1.6 \mu \mathrm{m}$ ), which are used to derive the fractional vegetation cover (FVC) product (EUMETSAT, 2008). The spatial resolution is about $0.04^{\circ}$ (about $4.5 \mathrm{~km}$ ). The time resolution of MSG allows us to have cloud-free estimations of LAI on the area.

\subsection{Influence of the calibration parameters on simulations}

A first set of 50 simulations has been carried out to evaluate the effects on the simulated hydrographs of the calibration parameters shown in Table 1. The most significant are used in the following in order to show how the parameters affect the simulations. 

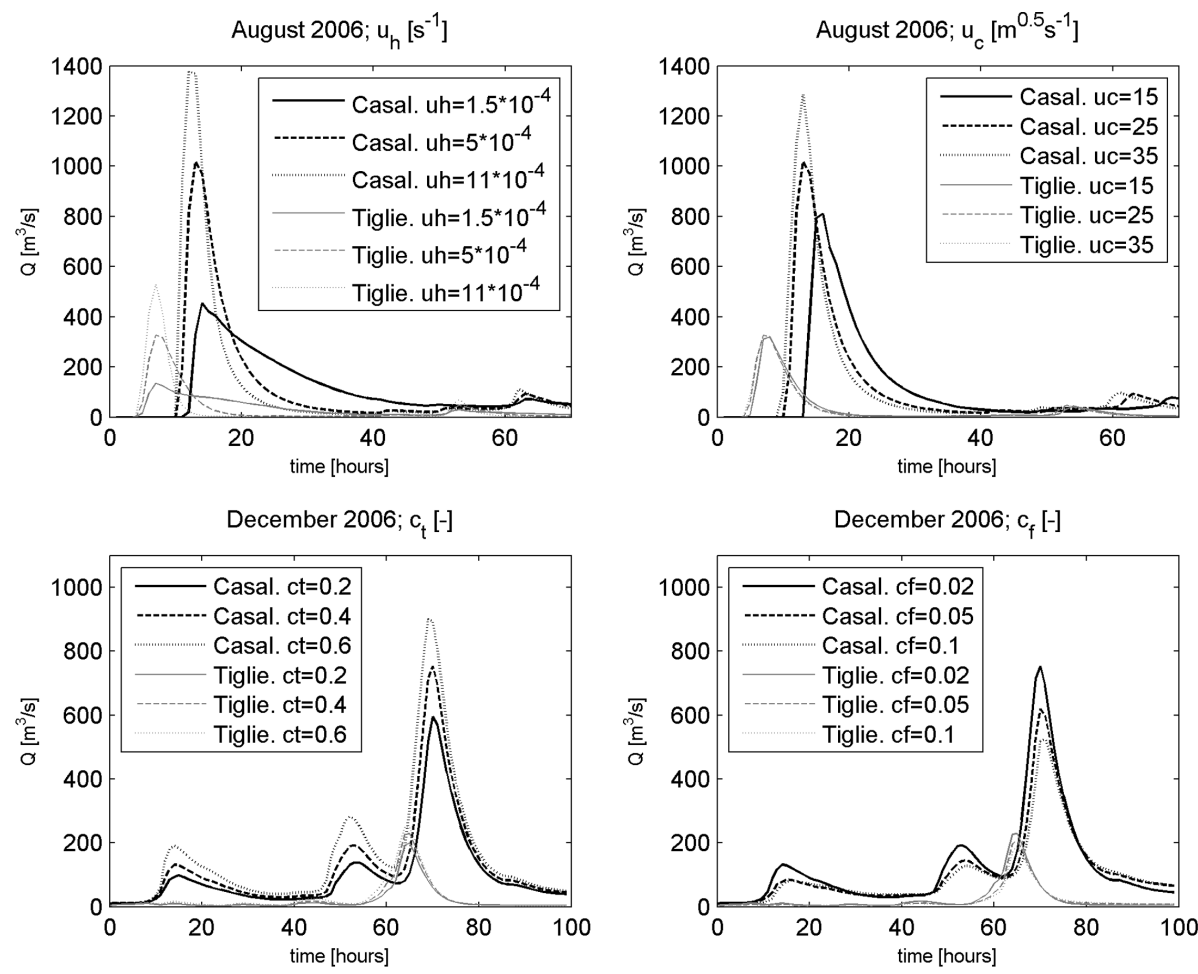

Fig. 5. Influence of the calibration parameters on hydrographs. $c_{\mathrm{t}}$ and $c_{\mathrm{f}}$ are the subsurface flow parameters while $u_{\mathrm{h}}$ and $u_{\mathrm{c}}$ are the overland and channel flow equation parameters.

The range of variation of the parameters has been defined based on prior knowledge of the parameter meaning, which defines their mathematical and physical range of validity (Beven and Binley, 1992; Maidment, 1992; Dingman, 2002). The ranges are reported in Table 2.

The parameters $u_{\mathrm{c}}$ and $u_{\mathrm{h}}$ impact the water flow on the surface. High values of these two parameters lead to narrow and highly peaked hydrographs. $u_{\mathrm{h}}$ has influence on the general shape of the hydrograph while $u_{\mathrm{c}}$ has an increasing influence with the increasing length of the channelled paths (e.g. large/elongated basins). It modifies the peak flow value as well as the peak arrival time.

The impact estimation of parameters $u_{\mathrm{h}}$ and $u_{\mathrm{c}}$ has been made considering a short period of simulation (16 to $18 \mathrm{Au}$ gust 2006) since they influence directly the overland and channel flow. The first subplot of Fig. 5 shows that $u_{\mathrm{h}}$ has a considerable influence on both the Tiglieto and Casalcermelli outlets. The peak values and the hydrograph shape have quite a large range of variation, while peak times are not significantly affected by this parameter.

The second subplot of Fig. 5 shows the influence of $u_{\mathrm{c}}$. It mainly affects the shape and the peak times on the Casalcermelli outlet section, while hydrographs of the Tiglieto outlet show negligible differences. Note that Casalcermelli has a drainage area that is one order of magnitude larger in respect to Tiglieto.
Table 2. Range of variation of the parameters used for the calibration process and minimum parameter gradient ( $\Delta$ Par) used for calibration with streamflow data.

\begin{tabular}{lllll}
\hline Parameter & Unit & Min & Max & $\Delta$ Par \\
\hline$c_{\mathrm{t}}$ & {$[-]$} & 0.15 & 0.65 & 0.01 \\
$c_{\mathrm{f}}$ & {$[-]$} & 0.01 & 0.1 & 0.01 \\
$u_{\mathrm{c}}$ & $\mathrm{m}^{0.5} \mathrm{~s}^{-1}$ & 15 & 60 & 1 \\
$u_{\mathrm{h}}$ & $\mathrm{s}^{-1}$ & 0.0002 & 0.0015 & 0.0001 \\
$R_{\mathrm{f}}$ & {$[-]$} & 0.5 & 50 & 0.5 \\
\hline
\end{tabular}

The parameter $c_{\mathrm{t}}$ is related to the soil field capacity and defines the fraction of water volume in the soil not available for percolation and subsurface flow. It has an impact on the dynamics of soil saturation between rain events: higher values of $c_{\mathrm{t}}$ reduce the soil drying time scale especially during the cold season, with consequently higher runoff coefficients for single rainfall events. However, the subsurface flow tends to vanish rapidly, because water level drops easily under the field capacity.

The parameter $c_{\mathrm{f}}$ controls both the velocity of subsurface flow and the dynamics of saturation of the single cells. Low values of $c_{\mathrm{f}}$ (i.e. low values saturated hydraulic conductivity) tend to cause the rapid saturation during rainfall events associated with slow subsurface flow increasing runoff production. Higher values of $c_{\mathrm{f}}$ produce a rapid subsurface flow with 

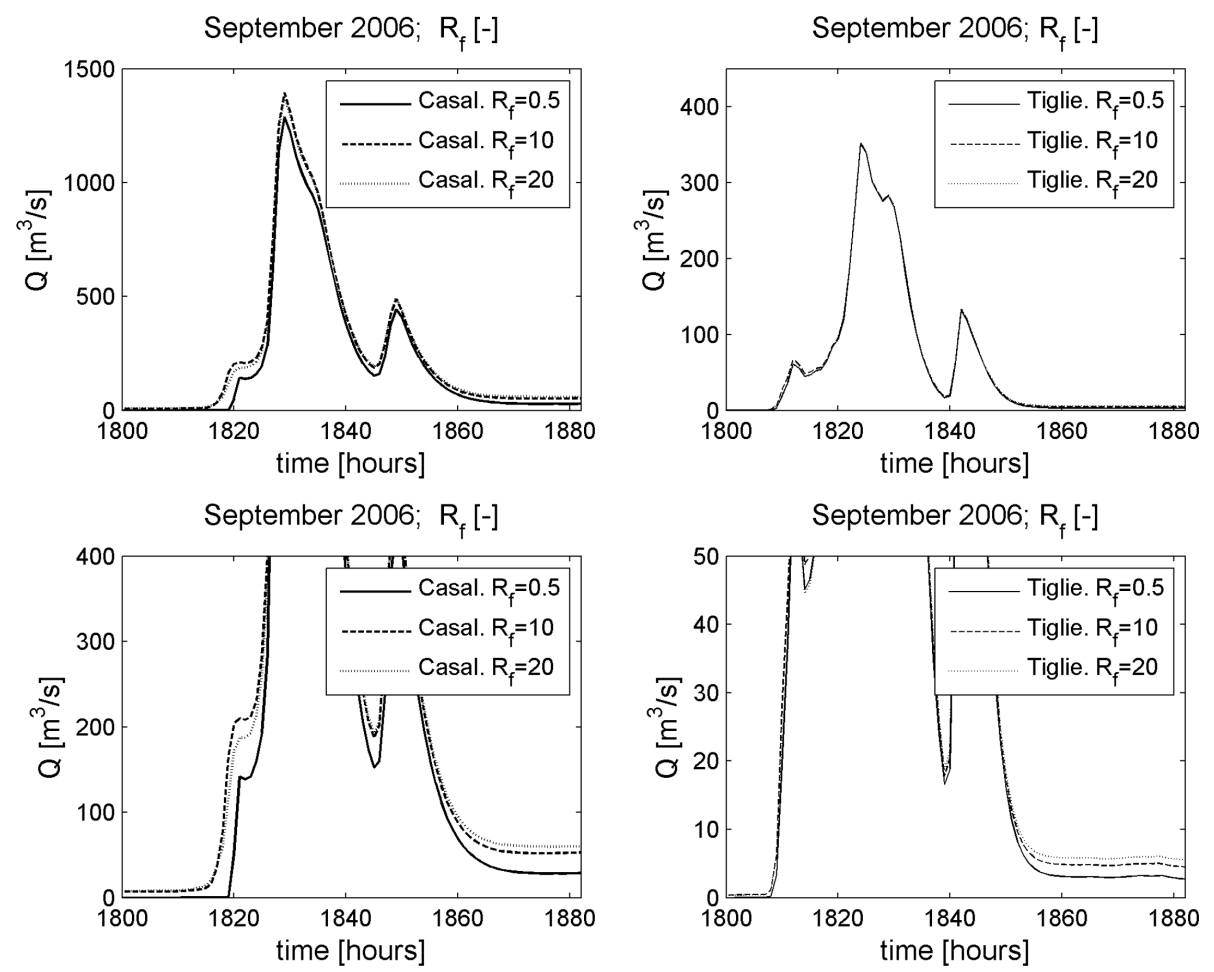

Fig. 6. Influence of the parameter $R_{\mathrm{f}}$ on hydrographs; both the outlet sections are considered. The same period is shown with different y-axis scales to highlight the differences for both high and low flows.

saturated areas that quickly concentrate along the drainage network.

The combination of the two soil parameters $c_{\mathrm{t}}$ and $c_{\mathrm{f}}$ controls the distribution of the volumes of soil and surface water in space and time, and it impacts soil humidity propagation. $c_{\mathrm{t}}$ and $c_{\mathrm{f}}$ influence the mass balance over long periods and regulate the exchanges between subsurface flow and runoff. The third and fourth panels in Fig. 5 show how they affect the tails of the hydrographs and the values of peak flows in the period between 7 and 10 December 2006. The effect of the combination of these two parameters is quite complex, and it is only partially represented in the figures. They must be calibrated over long periods of time using, at best, external soil information when available.

The parameter $R_{\mathrm{f}}$ regulates the response of the deep flow and mainly influences low flow regimes, while for larger basins it also affects high discharges. In Fig. 6 the period between 14 and 17 September 2006 is shown. The effects of $R_{\mathrm{f}}$ on the Tiglieto outlet are negligible during the flood while the influence on low flows is more relevant for both the outlet sections.

Particular remarks need to be made about $V_{\mathrm{Wmax}}$ - a measure of the capacity of the basin for storing water in its aquifer and deep soil layer.

It is not easy to define a value for $V_{\mathrm{Wmax}}$ that reproduces a correct or realistic distribution of the deep soil layer water storage throughout the basin due to the fact that this distribution is hard to observe. Tests made using different values of $V_{\mathrm{Wmax}}$ in a physically acceptable range and starting from the same initial condition show that the model has low sensitivity to this parameter when the period of simulation covers between 6-12 months. This is related to the slow temporal dynamic of the water table. If data series for very long simulations (many years) are available, the parameter $V_{\mathrm{Wmax}}$ can be re-calibrated and adjusted.

In the adopted scheme the initialization of the related state variable $V_{\mathrm{W}}(t)$ is more important than its upper limit. In fact, practice demonstrates that the definition of the water table initial condition $V_{\mathrm{W}}(t=0)$ evidently influences simulated discharge. A reasonable initial condition produces a rapid stabilization of the water table with dynamics driven by the water input from upper soil layer. Two considerations are made in order to define these: (i) in correspondence with the drainage network, the water table is generally next to soil surface, because it is continuously recharged by the upstream portions of catchment; (ii) the mountainous parts of the water table receive reduced contribution, because they drain small areas and are characterized by high gradients, and here the water table has lower levels. Based on these considerations, water table initial conditions are set as follows. $V_{\mathrm{W}}(t=0)$, in correspondence with channels, is set close to $V_{\mathrm{Wmax}}$. In the hillslopes the level of $V_{\mathrm{W}}(t=0)$ is estimated supposing it is inversely proportional to the downslope index $\alpha$ (Hjerdt et al., 2004). 

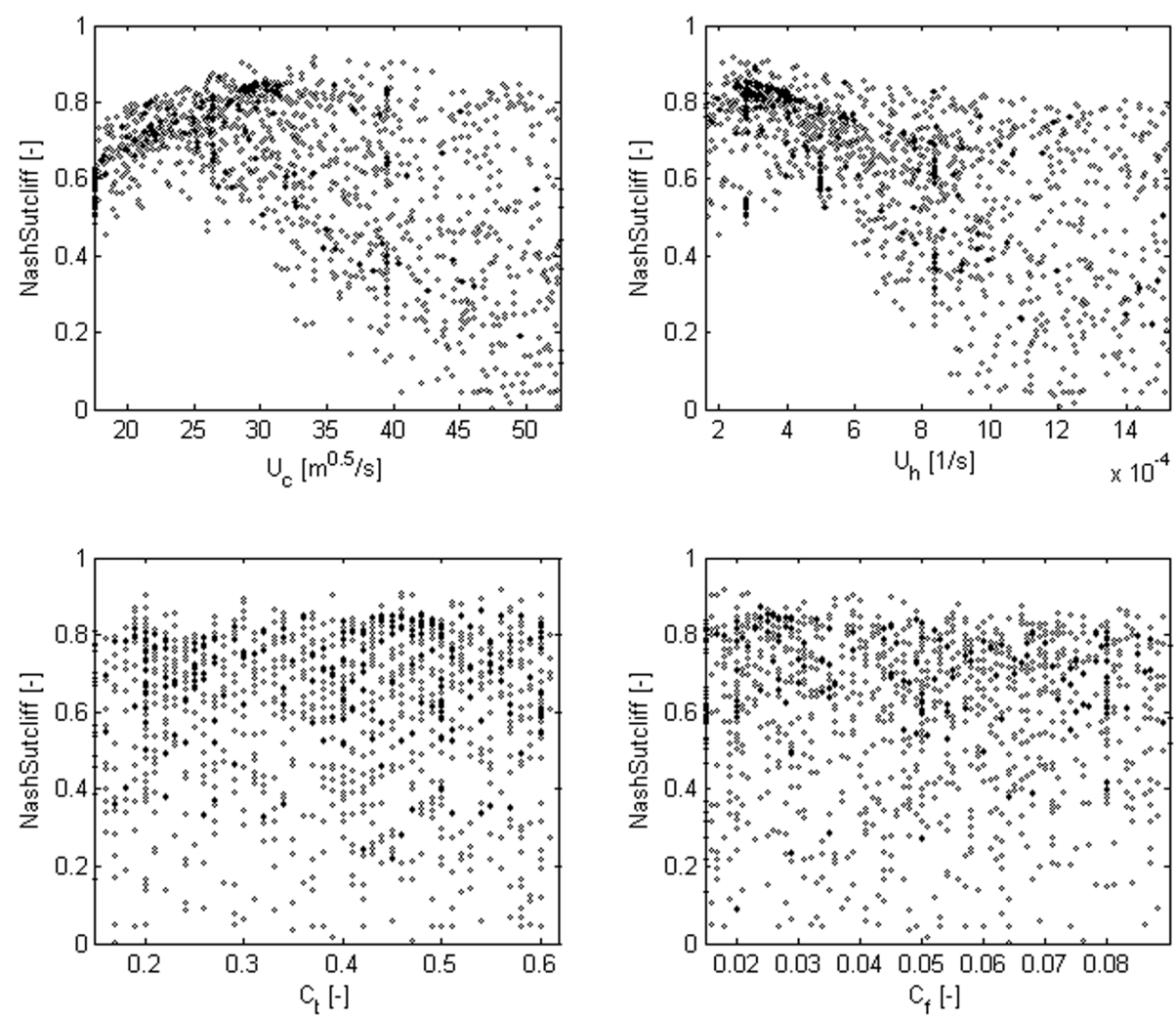

Fig. 7. Dot plot representation of the sensitivity analysis for the parameters $u_{\mathrm{c}}, u_{\mathrm{h}}, c_{\mathrm{t}}$, and $c_{\mathrm{f}}$.

In order to carry out a basic sensitivity analysis, we considered what appear to be the most sensitive parameters $\left(u_{\mathrm{c}}\right.$, $\left.u_{\mathrm{h}}, c_{\mathrm{t}}, c_{\mathrm{f}}\right)$ and a set of 2000 model runs has been generated using a Monte Carlo approach, sampling the parameters from a uniform distribution bounded by the parameter domain. The runs have been carried out on a sub-period of the calibration period where two major flood events occurred (July-September 2006). To show the results a dot plot representation (Beven and Binley, 1992; Shen et al., 2012) has been drawn using the Nash-Sutcliffe coefficient (NS) (Nash and Sutcliffe, 1970) as skill estimator (Fig. 7). From Fig. 7 it is possible to clearly identify a behavioural domain for $u_{\mathrm{h}}$ and $u_{\mathrm{c}}$, while a lot of uncertainty in the streamflow simulation due to $c_{\mathrm{f}}$ and $c_{\mathrm{t}}$ is present. This could be due to the very nonlinear relationship that connects these last two parameters with streamflow.

All these simulations highlighted another important feature of the model. Because of its internal structure, similarly to other complete hydrological models, it is possible to map different processes (Reusser et al., 2009) and therefore different parts of the hydrograph, onto the parameters, so that different parts of the hydrograph time series can be used separately to better identify model parameter values. Further analysis is needed to show sensitivity to spatial and temporal resolution.

\subsection{Standard calibration based on streamflow data}

The model has been firstly calibrated with a standard approach based on streamflow data. The dataset collected for the period 1 June to 31 December 2006 is particularly suitable for calibration under different hydrological conditions as it contains a range of significant floods and a preceding drought period. Runs of the model have been carried out for the whole year 2006, but the first five months are considered as model startup to ensure that the initial conditions do not affect the results.

The first part of the calibration period is quite dry with an absence of precipitation for more than two months. A very intense and persistent event started on 16 August 2006 and lasted about $10 \mathrm{~h}$ with peak rainfall intensities larger than $70 \mathrm{~mm} \mathrm{~h}^{-1}$. On 14 September 2006 another intense event with a $24 \mathrm{~h}$ duration and considerable rainfall accumulation took place.

For the calibration period we referred to empirical formulations that use wind speed and air temperature data to estimate the bulk transfer coefficient for heat and moisture (Deardoff, 1968). They do not account for vegetation variability.

Several skill estimators are considered in order to evaluate the performance of Continuum: Nash and Sutcliffe (1970), Chiew and McMahon (1994), correlation 

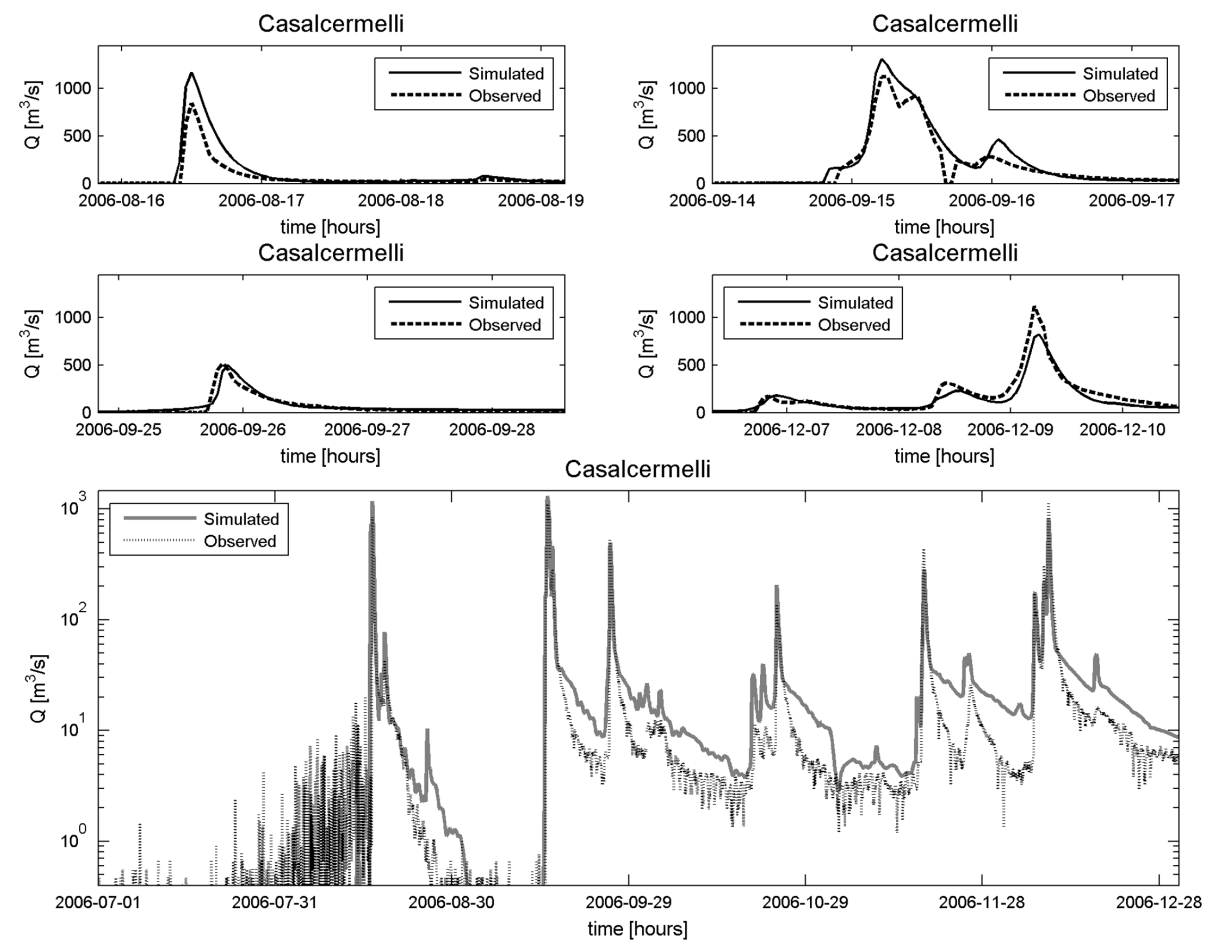

Fig. 8. Comparison between observed and simulated hydrographs for the calibration period for Casalcermelli outlet section.

coefficient (CORR), root-mean-square error (RMSE) and percentage error on six flood events in the period. The first three estimators assume the value 1 if observation and simulation match $100 \%$, while the other estimators tend to be 0 for a perfect simulation.

$V_{\mathrm{WMax}}$ has not been considered for calibration for the reasons already explained, and it has been set to the value $V_{\mathrm{WMax}}=1500 \mathrm{~mm}$.

The calibration has been performed in two steps. Initially, to reduce their range of variation, the two overland flow parameters have been calibrated on a short time period (16 to 18 August 2006). The errors on peak flow and on peak time on both the outlet sections have been minimized. Finally, a global calibration has been made including the three soil parameters $c_{\mathrm{t}}, c_{\mathrm{f}}$ and $R_{\mathrm{f}}$ maximizing the Nash-Sutcliffe coefficient, which is one of the most commonly used skill estimators in hydrology to compare observed and simulated hydrographs (Legates and McCabe, 1999). This has been carried out by varying parameter values in their range of validity following an iterative brute-force approach. Two iterations have been done; the minimum gradient varies for each parameter and it is reported in Table 2. Table 3 reports the set of parameters obtained by the calibration procedure.

Table 4 shows the skill estimators calculated for the entire simulation; Table 5 reports the percentage errors on peak flow (PPE) for the two outlet sections, Tiglieto and Casalcermelli. Figures 8 and 9 report the simulated hydrographs compared with observations; we plot the entire simulation
Table 3. Set of parameters obtained by the calibration.

\begin{tabular}{lccccc}
\hline Parameter & $R_{\mathrm{f}}[-]$ & $c_{\mathrm{f}}[-]$ & $c_{\mathrm{t}}[-]$ & $u_{\mathrm{h}}\left[\mathrm{s}^{-1}\right]$ & $u_{\mathrm{c}}\left[\mathrm{m}^{0.5} \mathrm{~s}^{-1}\right]$ \\
\hline Calibrated value & 1 & 0.02 & 0.52 & $5 \times 10^{-4}$ & 29 \\
\hline
\end{tabular}

Table 4. Values of skill estimators for the whole calibration period.

\begin{tabular}{lcccc}
\hline Outlet section & $\begin{array}{c}\text { RMSE } \\
{\left[\mathrm{m}^{3} \mathrm{~s}^{-1}\right]}\end{array}$ & $\begin{array}{c}\text { Nash and } \\
\text { Sutcliffe }[-]\end{array}$ & $\begin{array}{c}\text { Chiew and } \\
\text { McMahon [-] }\end{array}$ & CORR [-] \\
\hline Casalcermelli & 1.84 & 0.89 & 0.85 & 0.95 \\
Tiglieto & 1.62 & 0.70 & 0.76 & 0.90 \\
\hline
\end{tabular}

and the four most important events that occurred during the calibration period. The skill estimator values synthesize the good performance of the model for both outlets, and Figs. 8 and 9 highlight the capability of the model in reproducing the observed hydrographs in different discharge regimes.

\subsection{Validation}

Validation has been carried out during the period from 1 June 2009 to 31 December 2009. During the summer only a few precipitation events occurred with negligible ground effects. Consistent rainfall events started in October and the most relevant occurred in November and December. Similarly to what was done for the model calibration, a warm-up 

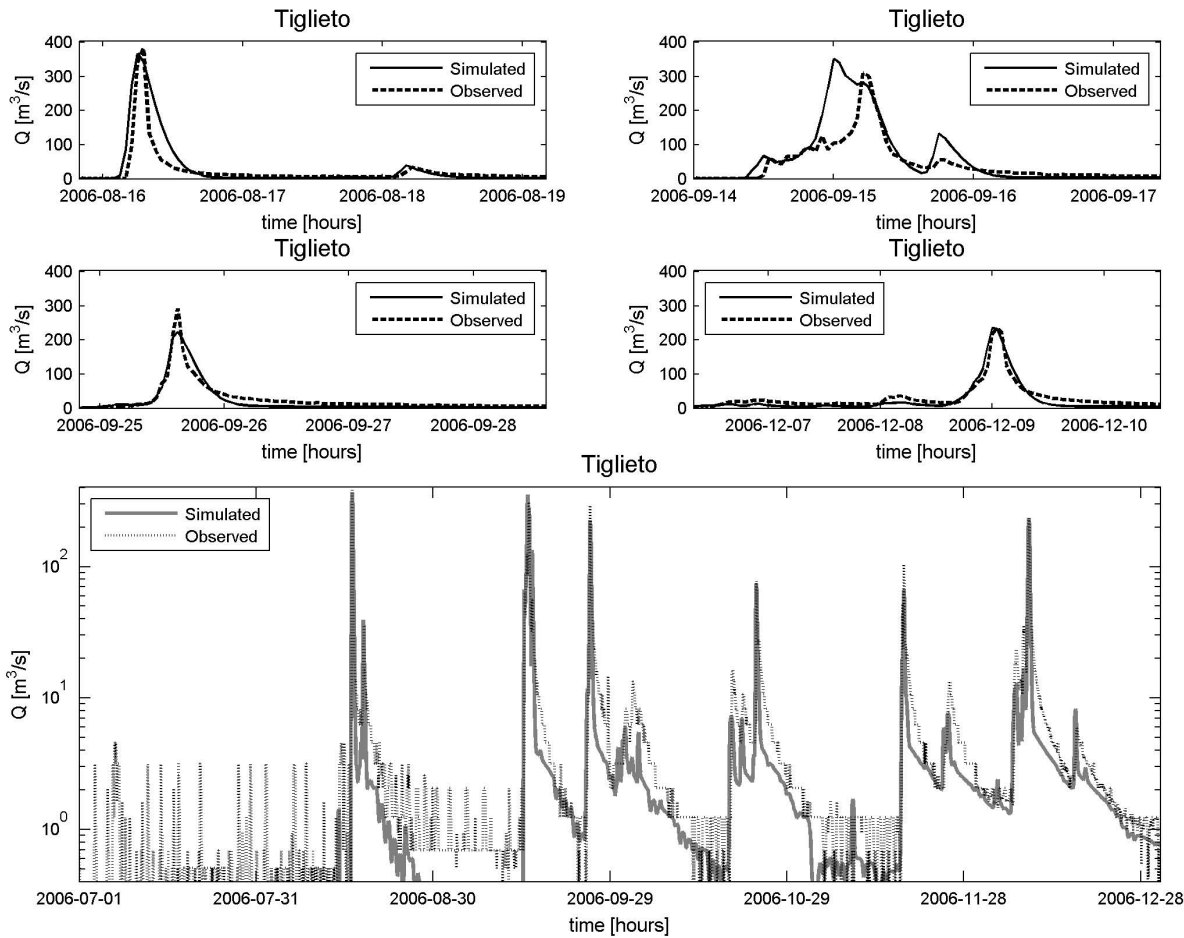

Fig. 9. Comparison between observed and simulated hydrographs for the calibration period for Tiglieto outlet section.

Table 5. Values of percentage error for the peak flows (PPE) of the main events that occurred during the calibration.

\begin{tabular}{lrr}
\hline Event date & $\begin{array}{r}\text { Casalcermelli } \\
\text { PPE [\%] }\end{array}$ & $\begin{array}{r}\text { Tiglieto } \\
\text { PPE [\%] }\end{array}$ \\
\hline 16 Aug 2006 & 27 & 7 \\
14 Sep 2006 & 8 & 13 \\
25 Sep 2006 & -2.3 & -17 \\
23 Oct 2006 & 41 & 4 \\
17 Nov 2006 & -40 & -42 \\
9 Dec 2006 & -26 & 2 \\
\hline
\end{tabular}

period of five months has been considered and the simulation started 1 January 2009.

The bulk transfer coefficient for heat $C_{\mathrm{H}}$ used in the energy balance equations is in general estimable by using empirical expressions that depend on wind speed, pressure and on vegetation characteristics that define the neutral transfer coefficient $C_{\mathrm{HN}}$. The vegetation parameterization is often derived by literature values, and it is considered constant in space and time because of the difficulty of evaluation in a real context. By using proper models that describe the vegetation and soil interaction with the atmosphere, it is possible to produce a more detailed $C_{\mathrm{HN}}$ estimation that takes into account the vegetation spatial distribution and its seasonal variability. In this work the $C_{\mathrm{HN}}$ estimation is carried out using a variational assimilation scheme as described in Caparrini and
Table 6. Values of skill estimators for the whole validation period.

\begin{tabular}{lcccc}
\hline Outlet section & $\begin{array}{c}\text { RMSE } \\
{\left[\mathrm{m}^{3} \mathrm{~s}^{-1}\right]}\end{array}$ & $\begin{array}{c}\text { Nash and } \\
\text { Sutcliffe [-] }\end{array}$ & $\begin{array}{c}\text { Chiew and } \\
\text { McMahon [-] }\end{array}$ & CORR [-] \\
\hline Casalcermelli & 1.06 & 0.91 & 0.89 & 0.96 \\
Tiglieto & 0.83 & 0.80 & 0.83 & 0.91 \\
\hline
\end{tabular}

Table 7. Values of percentage error for the peak flows (PPE) of the main events that occurred during the validation period.

\begin{tabular}{lrr}
\hline Event date & $\begin{array}{r}\text { Casalcermelli } \\
\text { PPE [\%] }\end{array}$ & $\begin{array}{r}\text { Tiglieto } \\
\text { PPE [\%] }\end{array}$ \\
\hline 9 Oct 2009 & 78 & 21 \\
2 Nov 2009 & 48 & \\
8 Nov 2009 & -12 & 20 \\
30 Nov 2009 & -10 & -15 \\
24 Dec 2009 & -25 & -11 \\
\hline
\end{tabular}

Castelli (2004); maps of $C_{\mathrm{HN}}$ are produced every 15 days for the entire validation period. The application of this model has been possible for the validation period only.

\subsubsection{Streamflow validation}

Table 6 reports the skill estimators for the whole validation period, while Table 7 reports the percentage errors of the peaks of the main flood events. 

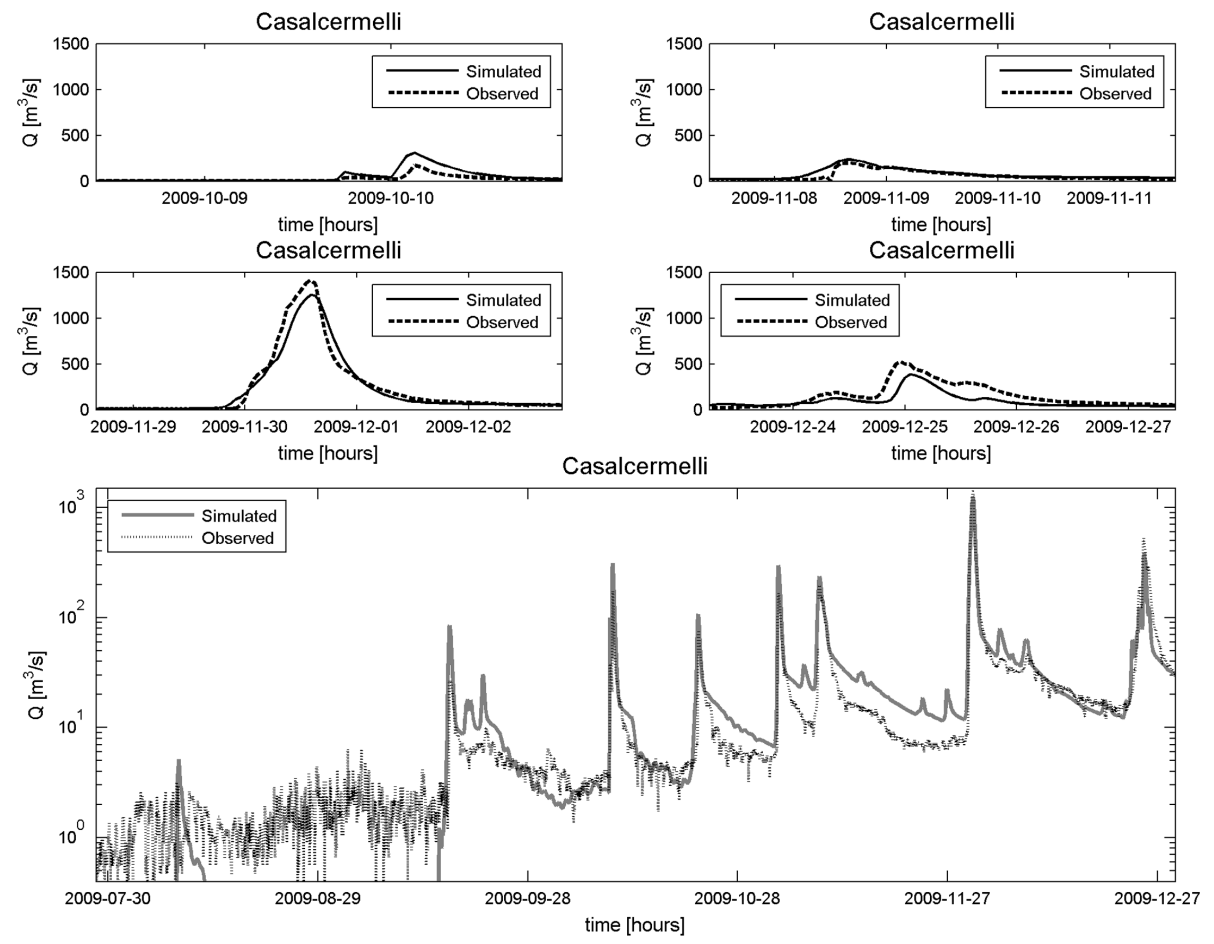

Fig. 10. Comparison between observed and simulated hydrographs for the validation period for Casalcermelli outlet section.

Skill estimators assume similar or better values during validation period with respect to the calibration period; this indicates the robustness of the model. Figures 10 and 11 report the simulated hydrographs compared with observations for the two outlet sections. As can be seen, the model reproduces well the observed discharges. In particular, during the most important flood events, Continuum simulates the shape of the hydrograph, the peak flows and the peak times surprisingly well.

In both calibration and validation periods, in few periods the differences between observed and simulated streamflow are not negligible; this can be due to the flash flood regime of the catchment, where the precipitation distribution could seriously hamper the performance of the model in reproducing the hydrograph due to input volume mismatch: this problem was highlighted in previous works facing the same challenging goal (Liu and Todini, 2002; Rigon et al., 2006, RuizVillanueva et al., 2012).

\subsubsection{Land surface temperature analysis}

The LSTs estimated by Continuum have been compared with LSTs retrieved by satellite measurements. The database of LST estimations provided by LAND SAT application facility (SAF) of EUMETSAT has been used (EUMETSAT, 2009). Land surface temperature estimations are available every $15 \mathrm{~min}$ with a spatial resolution of about $0.04^{\circ}$. Data are available for the validation period only. The retrieval of LST (Freitas et al., 2010) is based on clear-sky measurements from the MSG system in the thermal infrared window (MSG/SEVIRI channels IR108 and IR120). The analysis has been carried out for the period 1 June 2009 to 31 December 2009.

Due to the complex topography of the Orba basin, the LST satellite estimates cannot be directly compared to model outputs because of the following problems: (i) the georeferencing of model pixels and satellite pixels, (ii) the shadowing due to the presence of the mountains, (iii) the variation of the satellite viewing angle for the different detected areas, and (iv) the different spatial resolution (satellite-estimated spatial resolution is about $4.5 \mathrm{~km}$ while model output is about $0.1 \mathrm{~km}$ ). A land application model (F. Castelli, personal communication, 2009) that projects the radiance obtained from the model (obtained from the simulated LST) to the same geometry of the satellite observations solves these four cited issues. The land application model produces a correlation matrix that weights the model radiance to estimate the portion of energy of each model pixel that contributes to the energy of the satellite pixel. The application of the land surface model can be formalized as

$\overline{\varepsilon_{\mathrm{o}}} \cdot \overline{\mathrm{LST}}_{\mathrm{o}}^{4}=\mathbf{M} \cdot\left(\overline{\varepsilon_{\mathrm{m}}} \cdot{\overline{\mathrm{LST}_{\mathrm{m}}}}^{4}\right)$

where $\mathbf{M}$ is a matrix operator that weights the model output and maps it on the same grid of satellite data, $\varepsilon_{\mathrm{m}}$ and $\varepsilon_{\mathrm{O}}$ the model and the satellite thermal emissivity, $\mathrm{LST}_{\mathrm{m}}$ and $\mathrm{LST}_{\mathrm{o}}$ the modelled and the satellite-estimated land surface temperatures. The model assumes a constant $\varepsilon_{\mathrm{m}}$, and $\varepsilon_{\mathrm{o}}$ is estimated 

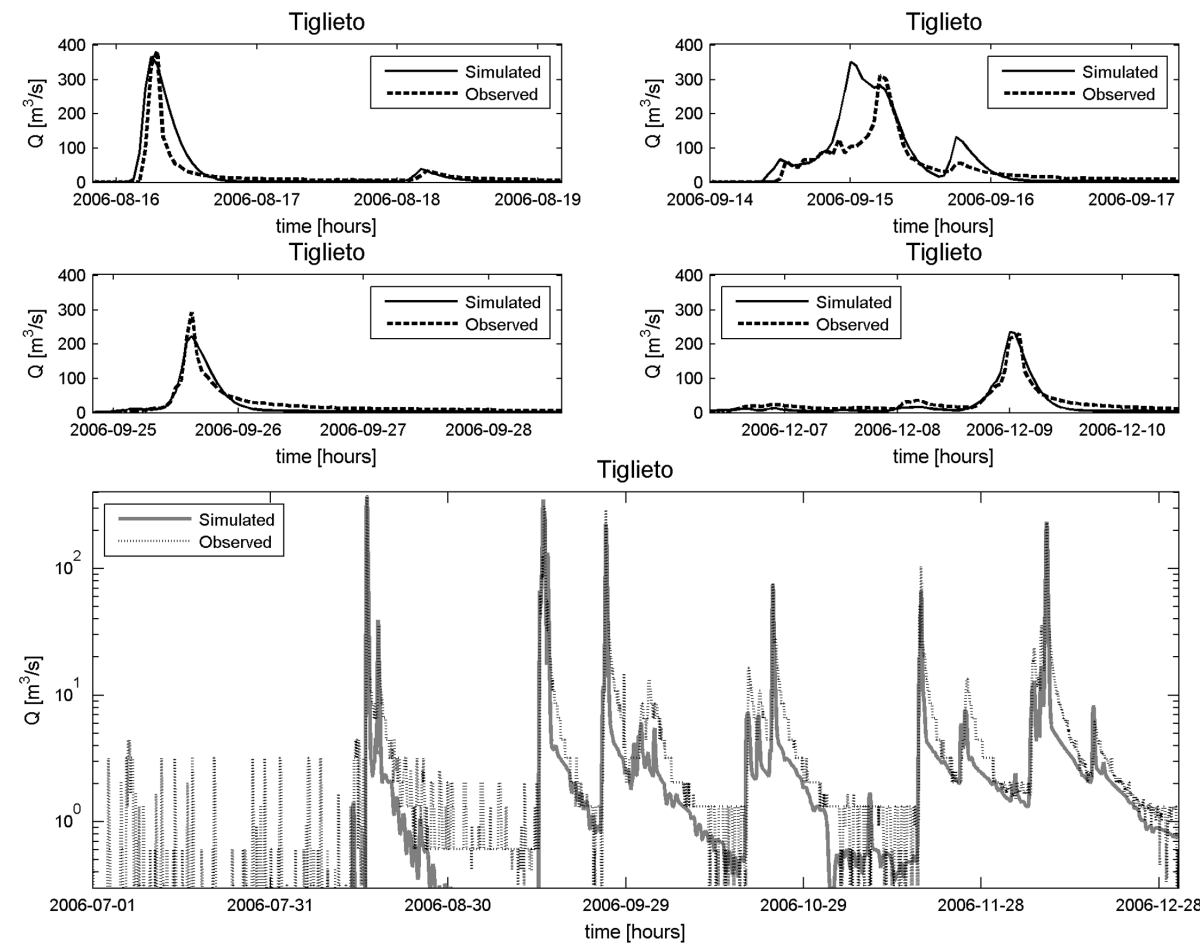

Fig. 11. Comparison between observed and simulated hydrographs for the validation period for Tiglieto outlet section.

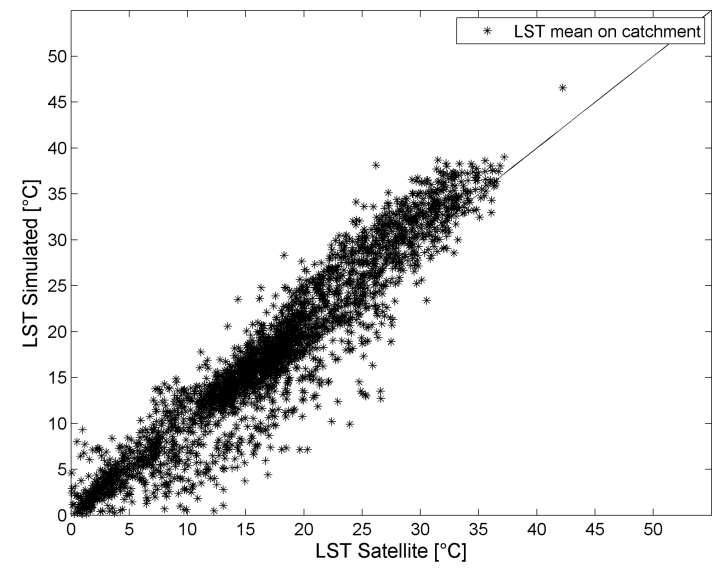

Fig. 12. Comparison between satellite estimates and simulated LST. Average LST at basin scale. The graph refers to the period from 1 June to 31 December 2009.

as the mean thermal emissivity of the two sensor channels used for LST-SAF retrieval.

We compared the basin mean LST and the LST of three selected pixels. The three pixels have been chosen from different areas of the basin to investigate the model behaviour in different environments. One pixel is in the mountainous part of the basin (we name it Mountain Pixel), one in the middle part (we name it Hill Pixel) and one near the outlet section in the flood plain (we name it Flat Pixel).

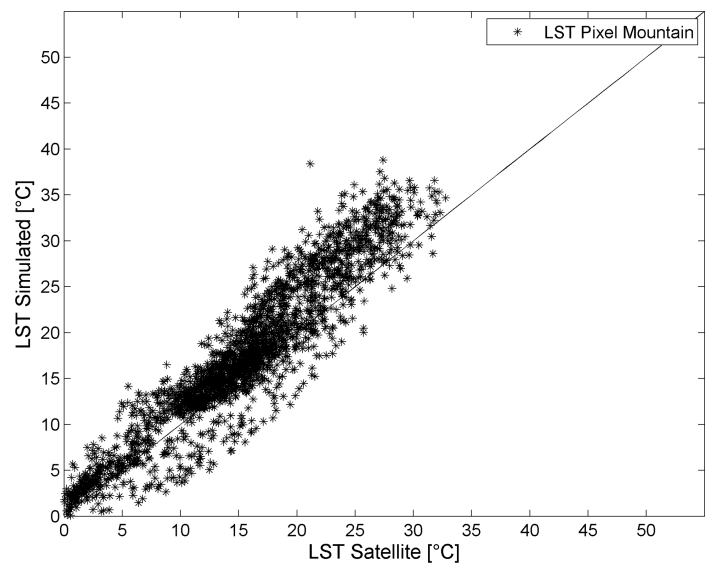

Fig. 13. Comparison between satellite estimates and simulated LST, mountain pixel. Graph refers to the period from 1 June to 31 December 2009.

Four skill estimators have been used to evaluate the performances of the model: the mean bias (BIAS), the root-meansquare error (RMSE), the mean absolute error (MAE) and the correlation coefficient (CORR).

Figures 12 to 15 report the scatter plot of satellite estimates and simulated LST for the mean basin comparison and for the pixel analysis.

The model slightly overestimates the LST during some periods of the warm season (Figs. 16 and 17), while it slightly underestimates LST during the cold season, in particular 


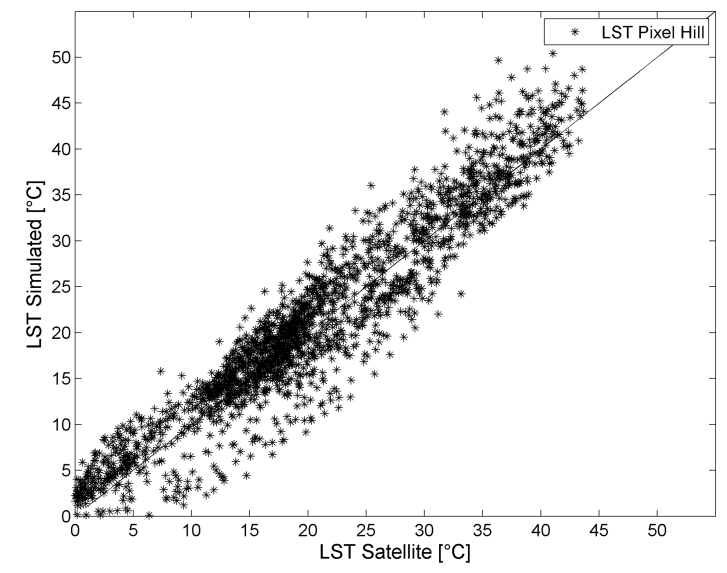

Fig. 14. Comparison between satellite estimates and simulated LST, hill pixel. Graph refers to the period from 1 June to 31 December 2009.

during the central hours of the day. This behaviour could be related to a slight overestimation of the model soil thermal inertia.

However, the general trends and diurnal cycle amplitude are well reproduced and the skill estimators show quite a good performance (see Table 8); BIAS, RMSE, and MAE are quite small, while CORR is next to 1 . Model errors are in most of the cases smaller than the root-mean-square error of satellite LST estimation with respect to in situ measurements, which is about $2-3{ }^{\circ} \mathrm{C}$ (Freitas et al., 2010). The model reproduces well the trend and the daily periodicity of LST (Figs. 16 and 17).

Figure 18 shows satellite estimates and simulated LST plotted with the mean incoming solar radiation at basin scale for a period of a few days. The LST is strongly related to the radiation, and the model is able to correctly reproduce the rapid changes in LST due to solar radiation variations.

The soil humidity is a factor that influences the thermal inertia and, as a consequence, the LST. We noted that, for example, the simulated LST overestimates the satellite estimates during a dry period at the beginning of summer (JuneJuly), where Continuum produces very low values of soil humidity at basin scale. This can be related to the fact that $\mathrm{AE}$ and CORR are similar for all the target areas (Table 8), while BIAS is higher and positive on mountain pixel where Continuum tends to dry the soil quickly because of the percolation and the soil humidity propagation. This behaviour becomes evident in Fig. 19 that depicts the RMSE map of LST distributed in the catchment layered over the DEM relief. RMSE high values tend to concentrate in mountainous areas. Another interpretation of this result is that in such areas the variance of LST is higher due to altitude variation, and this influences the statistics when aggregated at the MSG pixel size. However, we can deduce that a better LST simulation could be obtained by varying model parameters so as to obtain a different soil humidity distribution. Further analysis

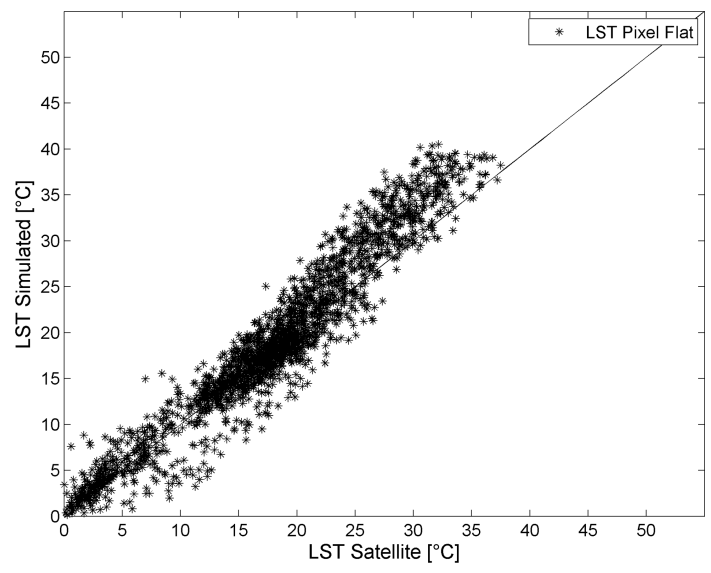

Fig. 15. Comparison between satellite estimates and simulated LST, flat pixel. Graph refers to the period from 1 June to 31 December 2009.

Table 8. Comparison of satellite estimates and simulated LST. Values of the skill estimators for the period: mean bias (BIAS), rootmean-square error (RMSE), mean absolute error (AE) and correlation coefficient (CORR).

\begin{tabular}{lcccc}
\hline Target area & $\begin{array}{c}\text { RMSE } \\
{\left[{ }^{\circ} \mathrm{C}\right]}\end{array}$ & $\begin{array}{c}\text { BIAS } \\
{\left[{ }^{\circ} \mathrm{C}\right]}\end{array}$ & $\begin{array}{c}\text { MAE } \\
{\left[{ }^{\circ} \mathrm{C}\right]}\end{array}$ & $\begin{array}{c}\text { CORR } \\
{[-]}\end{array}$ \\
\hline Basin & 3.69 & 0.24 & 2.27 & 0.96 \\
Mountain pixel & 5.53 & 2.09 & 2.88 & 0.94 \\
Hill pixel & 2.01 & 0.74 & 2.65 & 0.96 \\
Flat pixel & 2.94 & 1.08 & 2.24 & 0.96 \\
\hline
\end{tabular}

is needed to verify this hypothesis, and it was not carried out in this study. It is, however, interesting to note that LST could be actually a useful constraint in the calibration phase as discussed more in detail in the next section.

\subsection{Parameter calibration using land surface temperature and morphological data}

To demonstrate the possibility of reliably implementing the model in data-scarce environments, we performed a calibration supposing no streamflow data are available for the catchment under study. While it is always possible to find usable surrogates of meteorological variables using satellites or meteorological model analyses on one side and information about morphology and land cover is globally available at the needed resolution, on the other, it is often the case of not having reliable streamflow data in order to perform a standard hydrologic calibration of the model. In this exercise we used information that can be extracted by land cover maps, DEMs and the LST satellite estimations.

The analysis is focused on the most sensitive parameters $\left(u_{\mathrm{c}}, u_{\mathrm{h}}, c_{\mathrm{t}}, c_{\mathrm{f}}\right)$; the other two parameters have been set equal to the values $V_{\mathrm{Wmax}}=2000 \mathrm{~mm}, R_{\mathrm{f}}=1$ assuming that we have no information in support of their identification. $V_{\mathrm{Wmax}}$ 

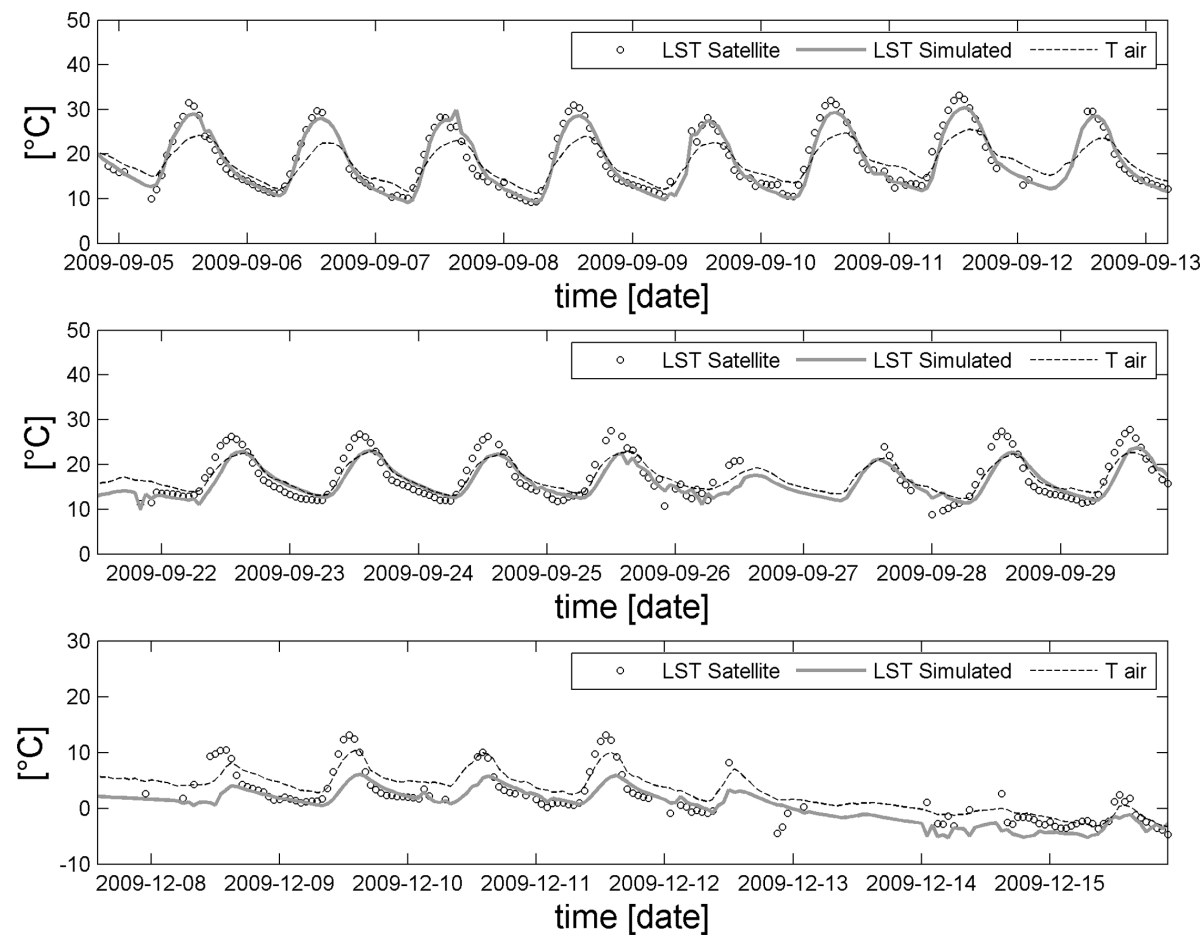

Fig. 16. Comparison between air temperature, satellite estimates and simulated LST for three periods belonging to the validation period: from 1 June to 31 December 2009. Average LST at basin scale.

is set to an average value for the environment considered, while $R_{\mathrm{f}}$ is set to one making the hypothesis of isotropy of the soil characteristics.

\subsubsection{Surface parameters $\left(u_{\mathrm{h}}\right.$ and $\left.u_{\mathrm{c}}\right)$}

The estimation of the overland and channel flow parameters has been carried out by exploiting geomorphologic information derived by the DEM. The idea is to calibrate the parameters against some hydrological time scales that can be derived by geomorphological information using wellestablished morphological relationships. One of the most influential parameters in that sense is the lag time $\left(t_{1}\right)$ of the basin, defined as the temporal distance between the centre of mass of the hydrograph and the centre of mass of the mean hyetograph at basin scale.

The lag time $\left(t_{1}\right)$ can be derived by geomorphologic features of the basin; we chose the formulation proposed by the National Resources Conservation Service (Ward and Trimble, 2003):

$t_{\mathrm{lo}}=\frac{L^{0.8} \cdot(S+1)^{0.7}}{1900 \cdot i_{\mathrm{f}}^{0.5}}$

where $L$ is the hydraulic length of the watershed, $i_{\mathrm{f}}$ the mean slope of the basin, $S$ a function of the curve number representing an index of the soil water storage capacity.

We generated a set of synthetic rainfall events (Eq. 7) with constant intensity in space and time to feed the model. In this
Table 9. Characteristics of the synthetic rainfall events related with the two surface parameters and the considered sections.

\begin{tabular}{lclrrr}
\hline Parameter & $P_{\text {cum }}[\mathrm{mm}]$ & $\begin{array}{l}\text { Reference } \\
\text { section }\end{array}$ & $\begin{array}{r}\text { Area } \\
{\left[\mathrm{km}^{2}\right]}\end{array}$ & $\begin{array}{l}t_{\mathrm{lo}} \\
{[\mathrm{h}]}\end{array}$ & $\begin{array}{r}\text { Event } \\
\text { duration } \\
{[\mathrm{h}]}\end{array}$ \\
\hline$u_{\mathrm{h}}\left[\mathrm{s}^{-1}\right]$ & $10,20, \ldots, 60,70$ & Tiglieto & 75 & 4.52 & 4 \\
$u_{\mathrm{c}}\left[\mathrm{m}^{0.5} \mathrm{~s}^{-1}\right]$ & $10,20, \ldots, 60,70$ & Casalcermelli & 800 & 11.6 & 10 \\
\hline
\end{tabular}

way we generate hydrographs that mainly depend on the geomorphologic characteristics of the basin. The features of the synthetic events are reported in Table 9. They are characterized by increasing accumulated rainfall while their duration is a function of the basin area. We calculated the simulated lag time of these synthetic events for each combination of the parameters and minimized the objective function:

$O f=\left|t_{\mathrm{lo}}-t_{\mathrm{lm}}\right|$

where $t_{\mathrm{lo}}$ is the $t_{1}$ derived by the geomorphologic characteristics of the basin and $t_{\mathrm{lm}}$ is the $t_{1}$ obtained by the model simulations.

The soil has been considered impermeable in order to eliminate the nonlinearities related to the wetness condition and to the infiltration-runoff process. The absence of infiltration and of dependency on humidity conditions at the beginning of the event (in the $t_{\mathrm{lo}}$ formula $S$ is set to 0 ) makes the model parameters that regulate subsurface and deep flow 

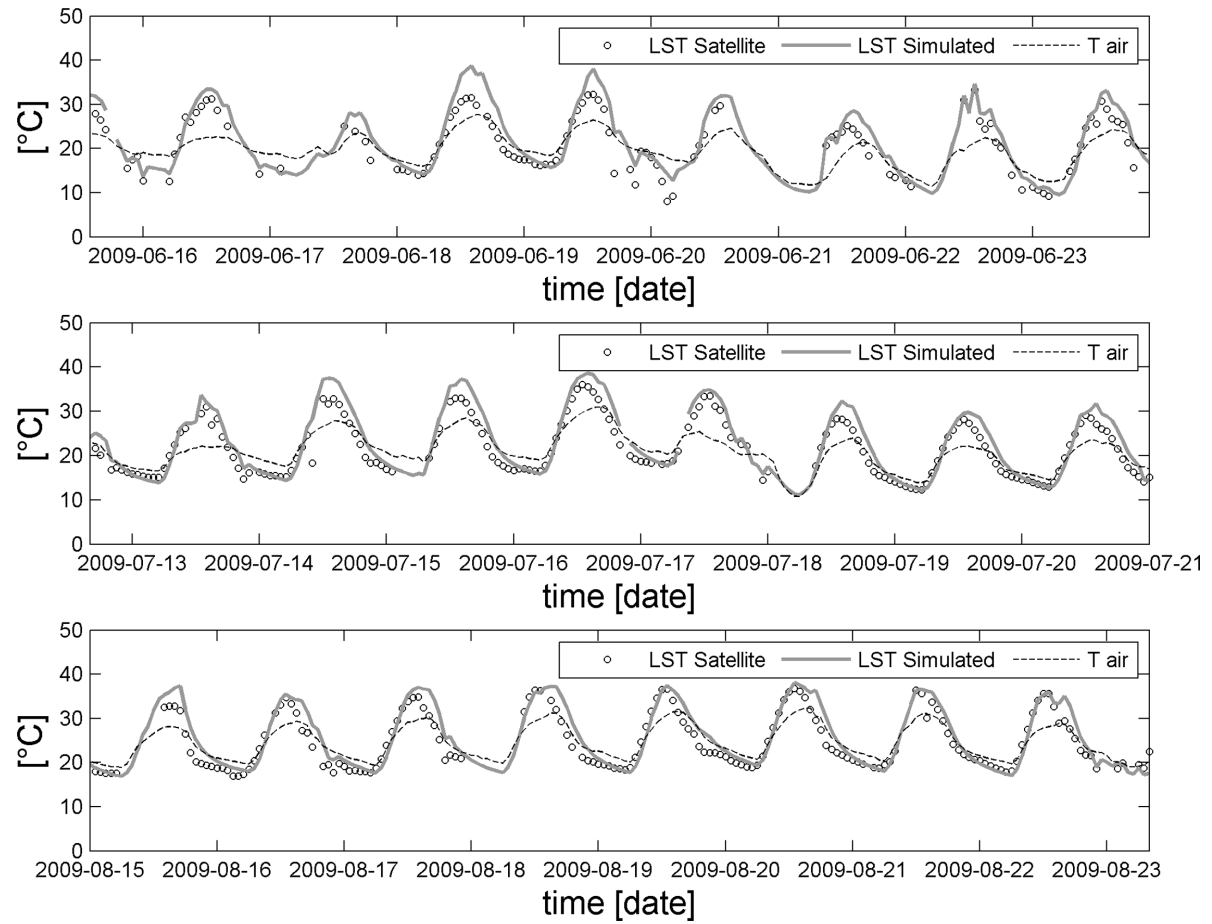

Fig. 17. Same as Fig. 16 but for different sub-periods.

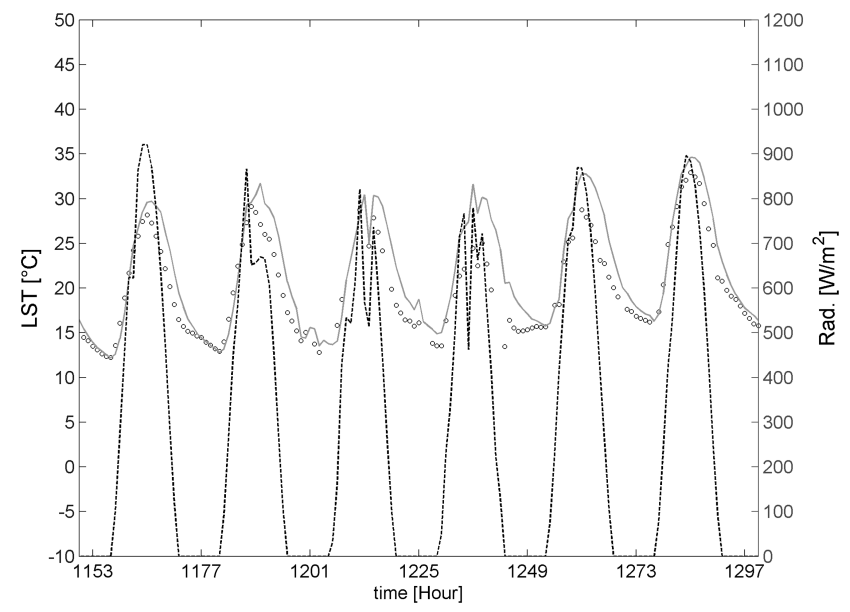

Fig. 18. Simulated (continuous grey line) and satellite-estimated (grey circles) LST plotted with observed net radiation (continuous grey black line). The graphs represent the basin-scale average values. A brief period of 6 days of June 2009 is shown.

$\left(c_{\mathrm{t}}, c_{\mathrm{f}}, R_{\mathrm{f}}\right.$ and $\left.V_{\mathrm{Wmax}}\right)$ irrelevant. $L$ and $i_{\mathrm{f}}$ are derived by the DEM.

On the basis of the analysis carried out in Sect. 3.3, it is clear that, in upstream sections, with reduced paths in channelled network, the influence of the parameter $u_{\mathrm{c}}$ is scarce; therefore a first guess value for $u_{\mathrm{c}}$ can be fixed and $u_{\mathrm{h}}$ calibrated. Once $u_{\mathrm{h}}$ is calibrated, $u_{\mathrm{c}}$ can be calibrated considering a downstream section. This procedure is iterated until
Table 10. Values of parameters $u_{\mathrm{c}}$ and $u_{\mathrm{h}}$ calibrated using geomorphologic data.

\begin{tabular}{|c|c|c|c|c|}
\hline \multirow[t]{2}{*}{ Parameter } & \multicolumn{2}{|c|}{$u_{\mathrm{c}}\left[\mathrm{m}^{0.5} \mathrm{~s}^{-1}\right]$} & \multicolumn{2}{|c|}{$u_{\mathrm{h}}\left[1 \mathrm{~s}^{-1}\right]$} \\
\hline & $\operatorname{Av}^{*}\left(u_{\mathrm{c}}\right)$ & $\operatorname{Std}^{* *}\left(u_{\mathrm{c}}\right)$ & $\mathrm{Av}^{*}\left(u_{\mathrm{h}}\right)$ & $\operatorname{Std}^{* *}\left(u_{\mathrm{h}}\right)$ \\
\hline & 29.42 & 1.93 & $4.58 \times 10^{-4}$ & $2.8 \times 10^{-5}$ \\
\hline
\end{tabular}

* Av stands for average; ${ }^{* *}$ Std stands for standard deviation.

the two parameters reach stability. In the case study we referred to the two gauged stations of Orba basin: Tiglieto $\left(A=75 \mathrm{~km}^{2}\right)$ and Casalcermelli $\left(A=800 \mathrm{~km}^{2}\right)$.

For each $P_{\text {cum }}$ the procedure rapidly converged $\left(N_{\text {iterations }}\right.$ $=3$ ).

The optimal values of $u_{\mathrm{c}}$ or $u_{\mathrm{h}}$ are different for different values of $P_{\text {cum }}$. This depends on the intrinsic characteristics of the model, and it is coherent with reality. The average of the optimal values and the standard deviation are calculated and reported in Table 10.

The mean values of the parameters have been used to proceed with the calibration.

\subsubsection{Subsurface parameters $\left(c_{t}\right.$ and $\left.c_{f}\right)$ - exploiting LST satellite estimate}

Once the surface flow parameters are estimated, it is necessary to calibrate the subsurface soil parameters. To do this the LST retrieved by satellite observations can be compared 


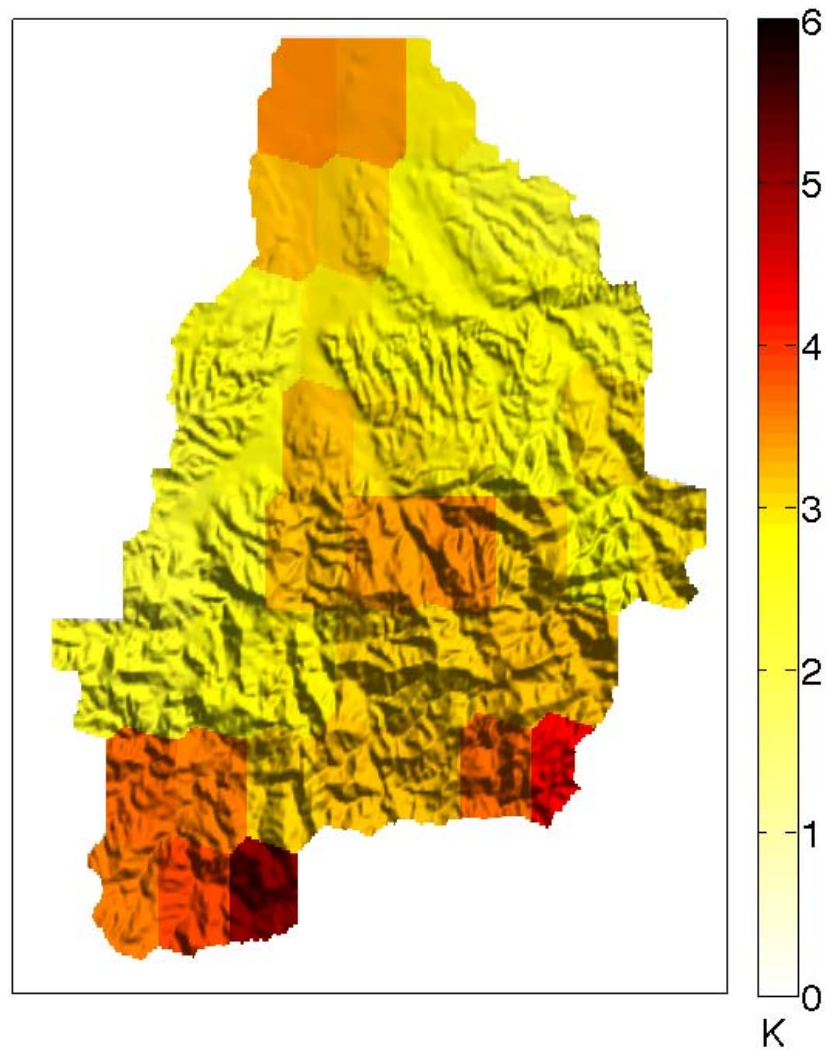

Fig. 19. RMSE map layered over the DEM relief. The value for each pixel is calculated as the mean of the RMSE on the whole validation period.

with that modelled by Continuum with the objective of minimizing the differences. LST is influenced by the soil characteristics and by the humidity content; in Continuum the two parameters $c_{\mathrm{t}}$ and $c_{\mathrm{f}}$ regulate the subsurface water propagations as well as the field capacity in each cell and, as a consequence, the humidity patterns through the basin.

The mean LST at basin scale ( $\mathrm{LST}_{\mathrm{Av}}$ ) has been considered, and the following score based on the BIAS between simulated $\left(\mathrm{LST}_{\mathrm{Avm}}\right)$ and satellite $\left(\mathrm{LST}_{\mathrm{Avo}}\right)$ estimates has been considered:

$\mathrm{BIAS}_{\mathrm{AV}}=\frac{1}{T_{\max }} \sum_{i=1}^{T_{\max }}\left(\mathrm{LST}_{\mathrm{Avo}, i}-\mathrm{LST}_{\mathrm{Avm}, i}\right)$

where $T_{\max }$ is the number of the considered temporal steps. The entire validation period has been used.

The score should guarantee that, on long periods, the temporal average of model LST is similar to that estimated by satellite data.

The BIAS $_{\mathrm{AV}}$ minimization returns the following values for the parameters: $c_{\mathrm{t}}=0.56[-]$ and $c_{\mathrm{f}}=0.03[-]$ with BIAS $_{\mathrm{AV}}=0.01$.

The value of $c_{\mathrm{t}}$ is weakly increased in respect to streamflow-based calibration as well as $c_{\mathrm{f}}$. This means that
Table 11. Values of skill estimators for the calibration and the validation periods obtained using $c_{\mathrm{t}}$ and $c_{\mathrm{f}}$ calibrated basing on the LST and $u_{\mathrm{c}}$ and $u_{\mathrm{h}}$ calibrated using geomorphologic data.

\begin{tabular}{lccccc}
\hline Outlet section & Period & $\begin{array}{c}\text { RMSE } \\
{\left[\mathrm{m}^{3} \mathrm{~s}^{-1}\right]}\end{array}$ & $\begin{array}{c}\text { Nash and } \\
\text { Sutcliffe [-] }\end{array}$ & $\begin{array}{c}\text { Chiew and } \\
\text { McMahon [-] }\end{array}$ & $\begin{array}{c}\text { CORR } \\
{[-]}\end{array}$ \\
\hline Casalcermelli & 2006 & 1.9 & 0.86 & 0.84 & 0.94 \\
& 2009 & 1.28 & 0.90 & 0.89 & 0.95 \\
Tiglieto & 2006 & 1.58 & 0.69 & 0.78 & 0.89 \\
& 2009 & 0.89 & 0.81 & 0.85 & 0.92 \\
\hline
\end{tabular}

to reduce the total bias of LST, larger values of field capacity and infiltration capacity at saturation are needed.

\subsubsection{Streamflow validation}

The final set of parameters has been used for simulating both calibration and validation periods, and the results are reported in Table 11 in terms of skill estimator values. The performance of the model in terms of streamflow reproduction is good. The skill estimators have overall values similar in respect to those reported in Tables 4 and 6; this proves that such calibration approach produces a reliable implementation of the model that can be replicated in data-scarce environments where real problems in finding reliable input-output series can be encountered.

In Figs. 20 and 21 the hydrographs obtained through the two calibration approaches are reported for the Casalcermelli outlet section. The flood events are really similar, while there are more evident differences in the baseflow and in the recession periods of the hydrographs.

\section{Discussion and conclusions}

The article describes a distributed and continuous hydrological model that balances the necessity for a complete description of hydrological cycle with a simple and versatile structure resulting in a limited number of parameters. It has been designed for a variety of purposes: flood forecast and simulation, water resource management and droughts. The model is able to reproduce the spatial-temporal evolution of soil moisture, energy fluxes, surface soil temperature and evapotranspiration. Moreover, it can account for seasonal vegetation variability in terms of interception and evaporation. Deep flow and water table evolution are modelled with a simple scheme that reproduces the main physical characteristics of the process and a distributed interaction between water table and soil surface with a low level of parameterization.

The introduction of the so-called "force-restore" equation for the surface energy balance allows the LST estimation and makes the model feasible to exploit remote sensing data. These latter can be used for calibration or, more appropriately, in a data assimilation framework.

Referring to already tested calibration methodologies (Giannoni et al., 2005; Gabellani et al., 2008) and making some 

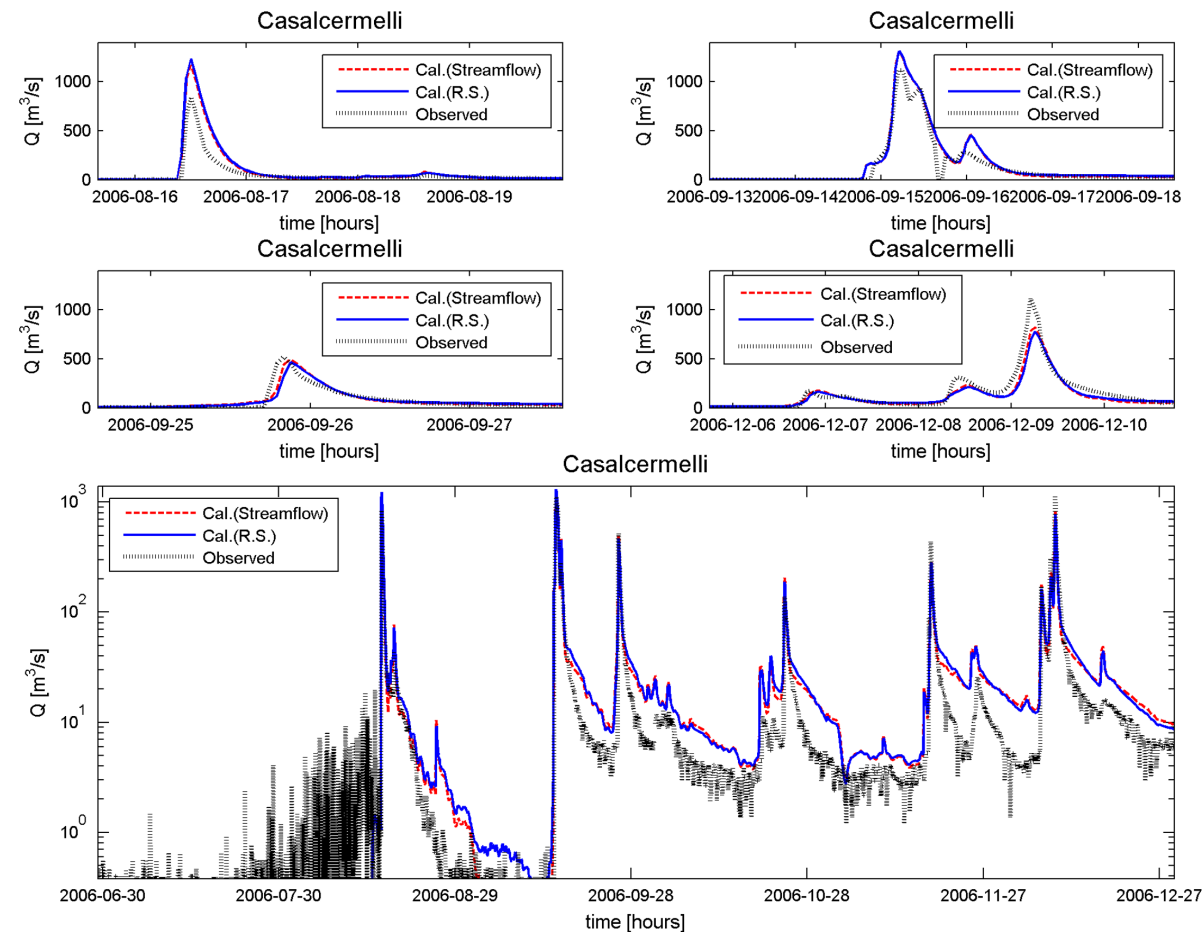

Fig. 20. Comparison of the streamflow simulations obtained with calibration using remote sensing data (Cal. R. S.) and calibration using streamflow data (Cal. Streamflow) for Casalcermelli outlet section for calibration period.
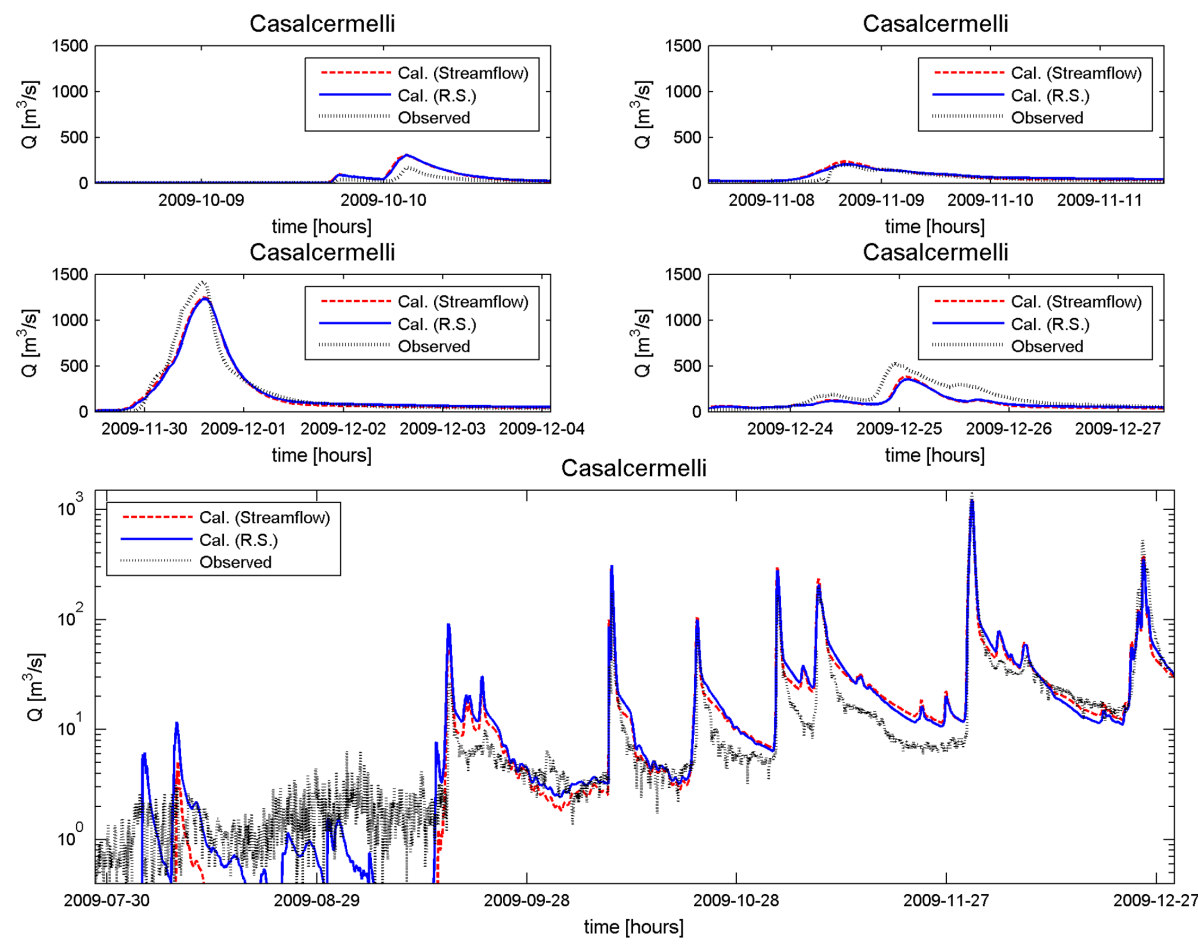

Fig. 21. Comparison of the streamflow simulations obtained with calibration using remote sensing data (Cal. R. S.) and calibration using streamflow data (Cal. Streamflow) for Casalcermelli outlet section for validation period. 
basic assumptions, the calibration task can be reduced to just six parameters at catchment scale that are then spatially distributed by means of simple assumptions on the physical processes that they describe. Consequently, the parameter space is really small for a distributed continuous model, and Continuum can be implemented with easily accessible data and territorial information (digital elevation model, basic soil and vegetation parameters).

If more detailed territorial information were available, the parameterization methodology could be approached reducing the number of assumptions and linking the parameters more tightly to territorial characteristics.

The sensitivity analysis has been carried out on five parameters: two parameters regulate the overland flow, the shape of the hydrograph and response time; two parameters are related to the soil characteristics and affect infiltration and relative soil humidity; and one parameter takes into account soil porosity and the ratio between vertical and horizontal saturated soil conductivity. A nice separation can be found between parameters in the fact that they influence quite distinct response of the model, with the result of further simplifying the calibration procedure.

Standard calibration and validation based on streamflow data have been carried out on different periods with reference to two different outlet sections of the Orba basin. These sections represent different characteristics in terms of soil use, slope and response time. The model produces good results in terms of discharge for both outlet sections. Further work is needed to introduce the modelling of the snow cover evolution and of the snowmelt in order to carry out multi-annual simulations where data are available.

Model initialization influences the simulation for quite a long period; in particular the definition of initial water table level is a sensitive choice. The ideal situation is to extend as far as possible the warm-up period, including a long period without rainfall events. The water table initialization methodology here is based on a possible spatial distribution of water table that exploits morphological constraints (Hjerdt et al., 2004).

Further validation analysis has been carried out comparing LST estimated by the model and satellite measurements at both pixel and basin scale. The results provide evidence that Continuum reliably models the LST dynamics at various temporal scales, with some periods of overestimation, particularly during the warmer hours of summer. During the cold season the modelled LST has a lower variability with respect to the satellite estimates, but here the percentage of reliable data is quite scarce because of the more frequent cloud covering, and this makes the comparison more uncertain.

The approach followed in the design of Continuum proposes concentrating the efforts in augmenting the number of state variables that are predicted by the model and those that are also observables by using classical or remote instruments of measure. Specific attention is paid to distributed variables (e.g. LST fields) that offer very different information when compared to integral measures (e.g. discharge time series).

The LST comparison showed potential for additional constraints to be used in the calibration phase or to be exploited in a more comprehensive assimilation framework. The distributed nature of the LST in comparison to traditional calibration time series (e.g. discharge data series) can add important information for a better estimation of state variables and parameter patterns. A demonstration of this potential is carried out by calibrating a sub-set of the parameters referring to LST satellite estimation and to morphologic information derived by the DEM. The results are comforting, and the proposed methodology led to a parameter set that well reproduces both satellite LST and streamflow observations, the latter used only in the validation phase. LST was successfully used to drive the calibration procedure. This was possible thanks to the model structure and the way parameters are treated and distributed in time and space. This could have a strong application impact in environments where reliable streamflow data are not available, given the worldwide availability of LST data.

\section{Appendix A}

\section{Surface flow equations}

The channeled surface flow equation that feeds into Eq. (1) is expressed as follows:

$q=u_{\mathrm{c}} \cdot \sqrt{\operatorname{tg}(\beta)} \cdot h^{\mathrm{a}}$

where $q$ is the flow per unit of width $\left[\mathrm{L}^{2} \mathrm{t}^{-1}\right], u_{\mathrm{c}}$ a friction coefficient $\left[\mathrm{L}^{(2-a)} \mathrm{t}^{-1}\right], \operatorname{tg}(\beta)$ the surface local slope in channels, and $h$ the depth of the flow in the channel [L]. The exponent $a$ is similar to the Manning's equation one. In general it varies between 1 and 5/3 (see e.g. Marchi and Rubatta, 1981). We set $a=1.5$ as representative of a mean behaviour. This choice is also consistent with the Darcy-Weisbach formulation in case of turbulent flow (Chow, 1959).

$\operatorname{tg}(\beta)$ is a downstream averaged local slope, evaluated as a mean slope of a branch of length $d^{*}$ downstream the actual pixel. It is estimated for the $i$-th cell as

$\operatorname{tg}\left(\beta_{i}\right)=\frac{1}{d^{*}} \sum_{j=1}^{n} \frac{z_{i}-z_{j}}{j}$

where $n=d^{*} / \Delta x, \Delta x[\mathrm{~L}]$ the square cell size of the discretized DEM, and $z_{j}$ the elevation at a distance $j \cdot \Delta x[\mathrm{~L}]$, for the application presented in the following paragraphs $\Delta x=100 \mathrm{~m}$ and $1000<d^{*}<2000 \mathrm{~m}$. This smoothed slope reduces the impact of local DEM errors and inconsistencies. 


\section{Appendix B}

\section{Subsurface flow equations}

In the following the equations that describe the subsurface flow mass balance are reported.

$$
\begin{cases}\frac{\mathrm{d} V}{\mathrm{~d} t}=r_{1}(t) & \text { for } V(t) \leq c_{\mathrm{t}} V_{\max } \text { and } r_{1}(t) \leq g(t) \\ \frac{\mathrm{d} V}{\mathrm{~d} t}=r_{1}(t)-f_{1} \frac{V(t)-c_{\mathrm{t}} V_{\max }}{V_{\max }\left(1-c_{\mathrm{t}}\right)} & \text { for } V(t)>c_{\mathrm{t}} V_{\max } \text { and } r_{1}(t) \leq g(t) \\ \frac{\mathrm{d} V}{\mathrm{~d} t}=f_{0}+\left(f_{1}-f_{\mathrm{o}}\right) \cdot \frac{V(t)}{V_{\max }} & \text { for } V(t) \leq c_{\mathrm{t}} V_{\max } \text { and } r_{1}(t)>g(t) \\ \frac{\mathrm{d} V}{\mathrm{~d} t}=f_{0}+\left(f_{1}-f_{\mathrm{o}}\right) \cdot \frac{V(t)}{V_{\max }}-f_{1} \frac{V(t)-c_{\mathrm{t}} V_{\max }}{V_{\max }\left(1-c_{\mathrm{t}}\right)} & \text { for } V(t)>c_{\mathrm{t}} V_{\max } \text { and } r_{1}(t)>g(t)\end{cases}
$$

The input $r_{1}(t)$ is obtained by the sum of the net rain (rain depleted by vegetation interception) and of the upstream overland flow. This allows the model to assess the re-infiltration.

The runoff $r_{2}(t)$ is

$$
\left\{\begin{array}{ll}
r_{2}(t)=r_{1}(t)-g(t) & \text { for } r_{1}(t)>g(t) \\
r_{2}(t)=0 & \text { for } r_{1}(t) \leq g(t)
\end{array} .\right.
$$

\section{Appendix C}

\section{Deep flow and water table equations}

The water table level is computed as

$h_{\mathrm{W} i}(t)=z_{i}-\frac{V_{\mathrm{W} m i}-V_{\mathrm{W} i}(t)}{\eta}$

where $z_{i}$ is the elevation of the $i$-th cell, $\eta$ the soil porosity and $V_{\mathrm{W} i}(t)$ the actual water content.

In the model, the equation is simplified assuming uniform soil porosity so that Eq. $(\mathrm{C} 1)$ becomes

$h_{\mathrm{W} i}(t)=z_{i}-V_{\mathrm{Wm} i}+V_{\mathrm{W} i}(t)$.

\section{Appendix D}

\section{Energy balance equations}

The thermal inertia is defined by the following equation:

$\varphi=\sqrt{C_{\text {soil }} \cdot K_{\text {soil }}}$

where $C_{\text {soil }}\left[\mathrm{ET}^{-1} \mathrm{~L}^{-3}\right]$ is the soil heat capacity and $K_{\text {soil }}$ $\left[\mathrm{Et}^{-1} \mathrm{~L}^{-1} \mathrm{~T}^{-1}\right]$ is the soil thermal conductivity. Both the terms depend on the soil characteristics, and they are estimated as proposed in Peters et al. (1997). $C_{\text {soil }}$ and $K_{\text {soil }}$ also depend on soil saturation degree $s w$ (e.g. $s w=V(t) / V_{\max }$ in Continuum). Consequently, they vary in time and they both increase when soil moisture increases. Their parameterization is relatively robust in terms of the values chosen to represent the soil characteristics, while it is fairly sensitive to the saturation degree.

$C_{\text {soil }}=(1-n) \cdot \rho_{\text {soil }} \cdot c_{\text {psoil }}+n \cdot s w \cdot \rho_{\text {water }} \cdot c_{\text {water }}$ where $n$ is the soil porosity [\%], $\rho_{\text {soil }}$ the soil density $\left[\mathrm{m} \mathrm{L}^{-3}\right]$, $c_{\text {psoil }}$ the soil specific heat $\left[\mathrm{E} \mathrm{m}^{-1} \mathrm{~T}^{-1}\right], s w$ the soil saturation degree $[-], \rho_{\text {water }}$ the water density $\left[\mathrm{mL}^{-3}\right]$, and $c_{\text {pwater }}$ the water specific heat $\left[\mathrm{E} \mathrm{m}^{-1} \mathrm{~T}^{-1}\right]$.

$K_{\text {soil }}=K_{\mathrm{e}} \cdot\left(k_{\text {ssoil }}-k_{\text {dsoil }}\right)+k_{\text {ssoil }}$

where $k_{\mathrm{ssoil}}$ is the saturated soil thermal conductivity $\left[\mathrm{EL}^{-1} \mathrm{~T}^{-1}\right]$ and $k_{\mathrm{dssoil}}$ is the dry soil thermal conductivity $\left[\mathrm{EL}^{-1} \mathrm{~T}^{-1}\right]$. The Kersten number is defined as

$K_{\mathrm{e}}=\left\{\begin{array}{l}\log _{10}(s w)+1 \text { for } s w \geq 0.1 \\ \log _{10}(0.1)+1 \text { for } s w<0.1\end{array}\right.$

The turbulent sensible heat flux is estimated using a bulk transfer approach based on bulk transfer formula (Deardoff, 1968):

$H=\rho \cdot c_{\text {p_air }} \cdot C_{\mathrm{H}} \cdot U \cdot\left(\mathrm{LST}-T_{\mathrm{a}}\right)$

where $c_{\mathrm{p} \_ \text {air }}\left[\mathrm{E} \mathrm{m}^{-1} \mathrm{~T}^{-1}\right]$ is the specific heat of air, $\rho\left[\mathrm{m} \mathrm{L}^{-3}\right]$ the air density, $C_{\mathrm{H}}[-]$ the bulk transfer coefficient for heat, $U\left[\mathrm{Lt}^{-1}\right]$ the wind velocity and $T_{\mathrm{a}}[\mathrm{T}]$ the air temperature at reference elevation.

The latent heat flux is defined as

$\mathrm{LE}=\rho \cdot \lambda_{\mathrm{LE}} \cdot C_{\mathrm{E}} \cdot U \cdot \beta_{\mathrm{f}} \cdot\left(e_{\mathrm{s}}^{*}-e_{\mathrm{a}}\right) \cdot 0.622 \cdot \frac{1}{P}$

where $\lambda_{\mathrm{LE}}\left[\mathrm{E} \mathrm{m}^{-1}\right]$ is the latent heat of vaporization, $\left(e_{\mathrm{s}}^{*}-e_{\mathrm{a}}\right)\left[\mathrm{m} \mathrm{t}^{-2} \mathrm{~L}^{-1}\right]$ the difference in vapour pressure between the surface (at saturation) and air at reference elevation, $C_{\mathrm{E}}[-]$ the bulk transfer coefficient for moisture, $\beta_{\mathrm{f}}$ $[-]$ a coefficient function of the soil saturation degree $s w$ as described in Castelli (1995) and Dingman (2002), and $P$ $\left[\mathrm{m} \mathrm{t}^{-2} \mathrm{~L}^{-1}\right]$ the atmospheric pressure. The soil moisture influences the latent heat flux and it links actual and potential evapotranspiration through the term $\beta_{\mathrm{f}}$. Since $H, C_{\text {soil }}$ and $K_{\text {soil }}$ depend on $s w$, their values affect LST in a fairly complex nonlinear way. The net result is that high values of soil moisture reduce the daily variability of LST.

The bulk transfer coefficient for heat and moisture can be estimated using empirical formulations (Deardoff, 1968) or could be yield by other models (Caparrini and Castelli, 2004). $C_{\mathrm{H}}[-]$ effectively represents the role of vegetation in the energy balance.

Acknowledgements. This work is supported by the Italian Civil Protection Department, and by the Italian Regions of Valle d'Aosta and Liguria. We acknowledge the Italian Civil Protection Department for providing us with the data from the regional meteorological observation networks. A special thanks to Fabio Castelli for his support and his advice.

Edited by: A. Bronstert 


\section{References}

Abbott, M. B., Bathurst, J. C., Cunge, J. A., O'Connell, P. E., and Rasmussen, J.: An introduction to the European Hydrological System - Système Hydrologique Européen, "SHE", 1: History and philosophy of a physically-based, distributed modelling system, J. Hydrol., 87, 45-59, 1986.

Anderson, R. M., Koren, V. I., and Reed, S. M.: Using SSRUGO data to improve Sacramento Model a priori parameter estimates, J. Hydrol., 320, 103-116, 2006.

Bartholmes, J. and Todini, E.: Coupling meteorological and hydrological models for flood forecasting, Hydrol. Earth Syst. Sci., 9, 333-346, doi:10.5194/hess-9-333-2005, 2005.

Bauer, S.: A modified Horton equation during intermittent rainfall, Hydrol. Sci. Bull., 19, 219-229, 1974.

Beven, K.: Prophecy reality and uncertainty in distributed hydrological modeling, Adv. Water Resour., 16, 41-51, 1993.

Beven, K.: TOPMODEL: a critique, Hydrol. Process., 11, 10691085, 1997.

Beven, K. and Binley, A. M.: The future of distributed models: model calibration and uncertainty prediction, Hydrol. Process., 24, 43-69, 1992.

Beven, K. and Freer, J.: A dynamic TOPMODEL, Hydrol. Process., 15, 1993-2011, 2001.

Bhumralkar, C. M.: Numerical experiments on the computation of ground surface temperature in an atmospheric general circulation model, J. Appl. Meteorol., 14, 1246-1258, 1975.

Blackadar, A. K.: Modeling the nocturnal boundary layer, in: Proceedings of the Third Symposium on Atmospheric Turbulence, Diffusion and air Quality, American Meteorological Society, Boston, Mass., 46-49, 1976.

Boni, G., Entekhabi, D., and Castelli, F.: Land data assimilation with satellite measurements for the estimation of surface energy balance components and surface control on evaporation, Water Resour. Res., 37, 1713-1722, 2001.

Burnash, R. J. C.: The NWS river forecast system-catchment modeling, in: Computer Models of Watershed Hydrology, edited by: Singh, V. J., Water Resources Publication, Highlands Ranch, Colorado, 311-366, 1995.

Burnash, R. J. C., Ferral, R. L., and McGuire, R. A.: A Generalized Streamflow Simulation System: Conceptual Modeling for Digital Computers, Joint Federal-State River Forecast Center, Sacramento, CA, 1973.

Campo, L., Caparrini, F., and Castelli, F.: Use of multi-platform, multi-temporal, remote sensing data for calibration of a distributed hydrological model: an application in the Arno basin, Italy, Hydrol. Process., 20, 2693-2712, 2006.

Caparrini, F. and Castelli, F.: Variational estimation of soil and vegetation turbulent transfer and heat flux parameters from sequences of multisensor imagery, Water Resour. Res., 40, W12515, doi:10.1029/2004WR003358, 2004.

Caparrini, F., Castelli, F., and Entekhabi, D.: Mapping of land atmosphere heat fluxes and surface parameters with remote sensing data, Bound.-Lay. Meteorol., 107, 605-633, 2003.

Caparrini, F., Castelli F., and Entekhabi, D.: Estimation of surface turbulent fluxes through assimilation of radiometric surface temperature sequences, J. Hydrometeorol., 5, 145-159, 2004.

Castelli, F.: Atmosphere modeling and hydrology prediction uncertainty, in: GNDCI, Proceedings of workshop on hydrometeorology: impacts and management of extreme floods, La Colombella,
Perugia, 1779-1794, 1995.

Castelli, F., Menduni, G., and Mazzanti, B.: A distributed package for sustainable water management: a case study in the Arno basin, The Role of Hydrology in Water Resources Management, IAHS Publ. 327, in: Proceedings of a symposium held on the island of Capri in October 2008, Italy, 2009.

Chiew, F. and Mc Mahon, T.: Application of the daily rainfallrunoff model MODHYDROLOG to 28 Australian catchments, J. Hydrol., 153, 383-416, 1994.

Chow, V. T.: Open-Channel Hydraulics, McGraw-Hill, New York, Illus, xviii + 680 pp., 1959.

Clark, M. P. and Kavetski, D.: Ancient numerical daemons of conceptual hydrological modeling: 1. Fidelity and efficiency of time stepping schemes, Water Resour. Res., 46, W10510, doi:10.1029/2009WR008894, 2010.

Deardorff, J. W.: Dependence of air-sea transfer coefficients on bulk stability, J. Geophys. Res., 73, 2549-2557, 1968.

Deardorff, J. W.: Efficient prediction of ground surface temperature and moisture with inclusion of a layer of vegetation, J. Geophys. Res., 783, 1889-1903, 1978.

DHI: MIKE SHE Flow Modules Manual, Danish Hydraulic Institute, Denmark, 2003.

Dickinson, R. E.: The force-restore method for surface temperature and its generalization, J. Climate, 1, 1086-1097, 1988.

Dickinson, R. E., Henderson-Sellers, A., and Kennedy, P. J.: Biosphere-Atmosphere Transfer 25 Scheme (BATS) Version 1e as Coupled to the NCAR Community Climate Model, NCAR/TN-387+STR, National Centre for Atmospheric Research, Boulder, Colorado, 72 pp., 1993.

Dingman, S.: Physical hydrology, 2nd Edn., Prentice-Hall, Inc., Englewood Cliffs, NJ, 2002.

Diskin, M. H. and Nazimov, N.: Linear reservoir with feedback regulated inlet as a model for the infiltration process, J. Hydrol., 172, 313-330, 1994.

Downer, C. W., Ogden, F. L., Martin, W. D., and Harmon, R. S.: Theory Development and applicability of the surface water hydrologic model CAS 2D, Hydrol. Process., 16, 255-275, 2002.

Dozier, J. and Frew, J.: Rapid calculation of terrain parameters for radiation modeling from digital elevation data, IEEE T. Geosci. Remote, 28, 963-969, doi:10.1109/36.58986, 1990.

Dunne, T. and Black, R. D.: An experimental investigation of runoff production in permeable soils, Water Resour. Res., 6, 478-490, 1970.

EUMETSAT: Product user manual, vegetation parameters, http:// landsaf.meteo.pt/ (last access: 10 March 2011), 2008.

EUMETSAT: Algorithm Theoretical Basis Document for Land Surface Temperature (LST), http://landsaf.meteo.pt/ (last access: 22 September 2011), 2009.

Freitas, S. C., Trigo, I. F., Bioucas-Dias, J. M., and Gottsche, F. M.: Quantify the uncertainty of Land Surface Temperature retrievals from SEVIRI/Meteosat, IEEE T. Geosci. Remote, 45, 523-534, 2010.

Gabellani, S., Silvestro, F., Rudari, R., and Boni, G.: General calibration methodology for a combined Horton-SCS infiltration scheme in flash flood modeling, Nat. Hazards Earth Syst. Sci., 8, 1317-1327, doi:10.5194/nhess-8-1317-2008, 2008.

Garrote, L. and Bras, R. L.: A distributed model for real-time forecasting using digital elevation models, J. Hydrol., 167, 279-306, 1995. 
Giannoni, F., Roth., G., and Rudari, R.: A Semi-Distributed Rainfall-Runoff Model Based on a Geomorphologic Approach, Phys. Chem. Earth, 25, 665-671, 2000.

Giannoni, F., Roth., G., and Rudari, R.: Can the behavior of different basins be described by the same model's parameter set? A geomorphologic framework, Phys. Chem. Earth, 28, 289-295, 2003.

Giannoni, F., Roth., G., and Rudari, R.: A procedure for drainage network identification from geomorphology and its application to the prediction of the hydrologic response, Adv. Water Resour., 28, 567-581, 2005.

Hijerdt, K. N., McDonnell, J. J, Seibert, J., and Rodhe, A.: A new topographic index to quantify downslope controls on local drainage, Water Resour Res., 40, W05602, doi:10.1029/2004WR003130, 2004.

$\mathrm{Hu}, \mathrm{Z}$. and Islam, S.: Prediction of ground surface temperature and soil moisture content by the force restore method, Water Resour. Res., 31, 2531-2539, 1995.

Julien, P. Y., Saghafian, B., and Ogden, F. L.: Raster-Based hydrologic modeling of spatially-varied surface runoff, AWRA, Water Resour. Bull., 31, 523-536, 1995.

Karsten, J., Gurtz, J., and Lang, H.: Advanced flood forecasting in Alpine watersheds by coupling meteorological observations and forecasts with a distributed hydrological model, J. Hydrol., 267, 40-52, 2002.

Kozak, J. A., Ahuja, L. R., Green, T. R., and Ma, L.: Modelling crop canopy and residue rainfall interception effects on soil hydrological components for semi-arid agriculture, Hydrol. Process., 21, 229-241, 2007.

Kumar, S. V., Reichle, R. H., Peters-Lidard, C. D., Koster, R. D., Zhan, X., Crow, W. T., Eylander, J. B., and Houser, P. R.: A land surface data assimilation framework using the land information system: description and applications, Adv. Water Resour., 31, 1419-1432, 2008.

Legates, D. R. and McCabe, G. J.: Evaluating the use of "goodnessof-fit" measures in hydrologic and hydroclimatic model validation, Water Resour. Res., 35, 233-241, 1999.

Lin, J. D.: On the Force-Restore method for prediction of ground surface temperature, J. Geophys. Res., 85, 3251-3254, 1980.

Liu, Z. and Todini, E.: Towards a comprehensive physically-based rainfall-runoff model, Hydrol. Earth Syst. Sci., 6, 859-881, doi:10.5194/hess-6-859-2002, 2002.

Liu, Z., Martina, M. L. V., and Todini, E.: Flood forecasting using a fully distributed model: application of the TOPKAPI model to the Upper Xixian Catchment, Hydrol. Earth Syst. Sci., 9, 347364, doi:10.5194/hess-9-347-2005, 2005.

Madsen, H.: Automatic calibration of a conceptual rainfall-runoff model using multiple objectives, J. Hydrol., 235, 276-288, 2000.

Maidment, D.: Handbook of Hydrology, McGraw-Hill, Inc., 1992

Marchi, E. and Rubatta, A.: Meccanica dei fluidi, Principi ed applicazioni, UTET, Torino, 1981

Middelkoop, H., Daamen, K., Gellens, D., Grabs, W., Kwadijk, J. C. J., Hang, H., Parmet, B. W. A. H., Schädler, B., Schulla, J., and Wilke, K.: Impact of Climate Change on Hydrological Regimes and Water Resources Management in the Rhine Basin, Climatic Change, 49, 105-128, 2001.

Mishra, S. and Singh, V.: Soil Conservation Service Curve Number (SCS-CN) Methodology, Kluwer Academic Publisher, 2003.
Nash, J. E. and Sutcliffe, J. V.: River flood forecasting through conceptual models I: a discussion of principles, J. Hydrol., 10, 282 290, 1970.

Noihan, J. and Planton, S.: Simple parameterization of land surface processes for meteorological models, Mon. Weather Rev., 117, 536-549, 1989.

O'Callaghan, J. F. and Mark, D. M.: The extraction of drainage networks from digital elevation data, Comput. Vis. Graph. Image Proc., 28, 323-344, 1984.

Peters, C. D., Blackburn, E., Liang, X., and Wood, E. F.: The effect of soil thermal conductivity parameterization on surface energy fluxes and temperature, Water Resour. Prog., 55, 1209-1224, 1997.

Reusser, D. E., Blume, T., Schaefli, B., and Zehe, E.: Analysing the temporal dynamics of model performance for hydrological models, Hydrol. Earth Syst. Sci., 13, 999-1018, doi:10.5194/hess-13999-2009, 2009.

Rey, J. M.: Modeling potential evapotranspiration of potential vegetation, Ecol. Model., 123, 141-159, 1999.

Rigon, R., Bertoldi, G., and Over, T. M.: Geotop: A Distributed Hydrological Model with Coupled Water and Energy Budgets, J. Hydro-Meteorol., 7, 371-388, 2006.

Risse, L., Liu, B., and Nearing, M.: Using Curve Number to Determine Baseline Values of Green-Ampt Effective Hydraulic Conductivities, Water Resour. Bull., 31, 147-158, 1995.

Ruiz-Villanueva, V., Borga, M., Zoccatelli, D., Marchi, L., Gaume, E., and Ehret, U.: Extreme flood response to short-duration convective rainfall in South-West Germany, Hydrol. Earth Syst. Sci., 16, 1543-1559, doi:10.5194/hess-16-1543-2012, 2012.

Saulnier, G. M., Beven, K., and Obled, C.: Including spatially variable effective soil depths in TOPMODEL, J. Hydrol., 202, 158$172,1997$.

Savenije, H. H. G.: Equifinality, a blessing in disguise?, Hydrol Process., 15, 2835-2838, 2001.

Schlosser, C. A., Speranskaya, N. A., Robock, A., Vinnikov, K. Y., and Xue, Y.: 18-Year Land-Surface Hydrology Model Simulations for a Midlatitude Grassland Catchment in Valdai, Russia, Mon. Weather Rev., 125, 3279-3296, 1997.

Shen, Z. Y., Chen, L., and Chen, T.: Analysis of parameter uncertainty in hydrological and sediment modeling using GLUE method: a case study of SWAT model applied to Three Gorges Reservoir Region, China, Hydrol. Earth Syst. Sci., 16, 121-132, doi:10.5194/hess-16-121-2012, 2012.

Sini, F., Boni, G., Caparrini, F., and Entekhabi, D.: Estimation of large-scale evaporation fields based on assimilation of remotely sensed land temperature, Water Resour. Res., 44, W06410, doi:10.1029/2006WR005574, 2008.

Todini, E. and Ciarapica, L.: The TOPKAPI Model, in: Mathematical Models of Large Watershed Hydrology, Chapter 12, edited by: Singh, V. P. and Frevert, D. K., Water Resources Publications, Littleton, Colorado, 2001.

Wang, J., Endreny, T. A., and Hassett, J. M.: Power function of hydraulic conductivity for a TOPMODEL-based infiltration routine, Hydrol. Process., 20, 3825-3834, 2006.

Ward, A. D. and Trimble, W.: Environmental Hydrology, 2nd Edn., CRC Press, 504 pp., 2003. 
Winchell, M., Gupta, H. V., and Sorooshian, S.: On the simulation of infiltration- and saturation-excess runoff using radar based rainfall estimates: effect of algorithm uncertainty and pixel aggregation, Water Resour. Res., 34, 2655-2670, 1998.

Winsemius, H. C., Savenije, H. H. G., Gerrits, A. M. J., Zapreeva, E. A., and Klees, R.: Comparison of two model approaches in the Zambezi river basin with regard to model reliability and identifiability, Hydrol. Earth Syst. Sci., 10, 339-352, doi:10.5194/hess10-339-2006, 2006.

Wooding, R. A.: A hydraulic modeling of the catchment-stream problem, 1. Kinematic wave theory, J. Hydrol., 3, 254-267, 1965.
Yang, K., Huang, G.-W., and Tamai, N.: A Hybrid Model for Estimating Global Solar Radiation, Solar Energy, 70, 13-22, 2001.

Yang, K., Koike, T., and Ye, B.: Improving estimation of hourly, daily, and monthly solar radiation by importing global data sets, Agr. Forest Meteorol., 137, 43-55, 2006.

Zhao, C.: Potential Vegetation Modeling with Variable Leaf Area Index in Semi-arid Grassland of Loess Plateau, China, IEEE T. Geosci. Remote, 5, 3311-3313, 2003. 